Sheffield

Hallam

University
Centre for

Regional Economic

and Social Research

\title{
Co-design in the WorkingWin programme: good practice and learning
}

May 2020 


\section{Co-design in the WorkingWin programme: good practice and learning}

Christina Beatty, Richard Crisp and Tony Gore

Centre for Regional Economic and Social Research

Sheffield Hallam University

May 2020

DOI: 10.7190/cresr.2020.8326265687 


\section{Acknowledgements}

The research team would like to thank Andrea Fitzgerald and Katy Pugh from the Sheffield City Region for their guidance and support. Adam Whitworth from the University of Sheffield also provided valuable advisory support during all phases of the project. We would also like to thank the many respondents who have made time for us during their busy schedules to talk to us about their experience of being part of WorkingWin. Finally, thanks are due to our colleague Sarah Ward at CRESR for help in preparing this report. 


\section{Contents}

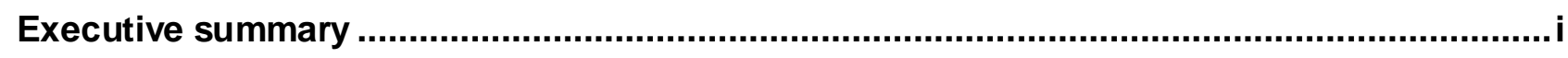

1. Introduction

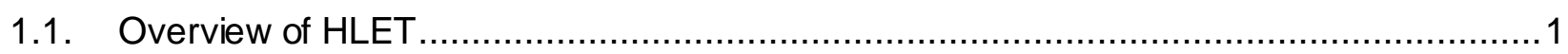

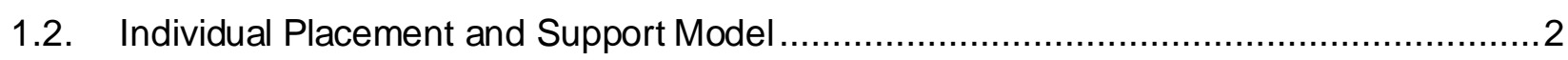

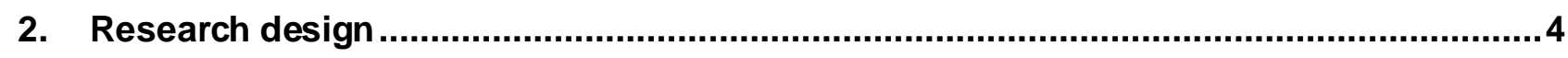

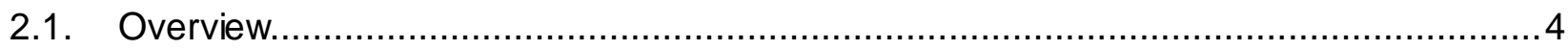

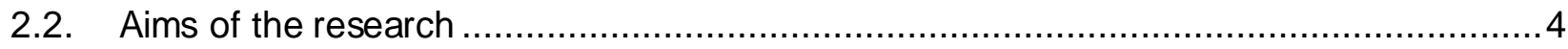

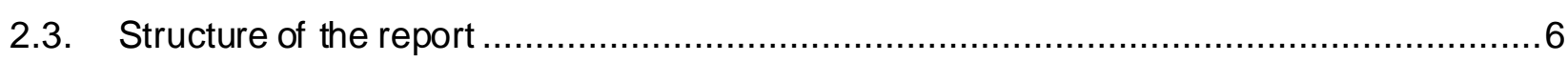

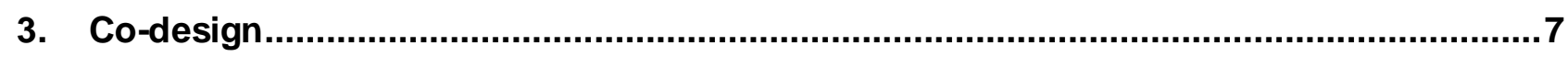

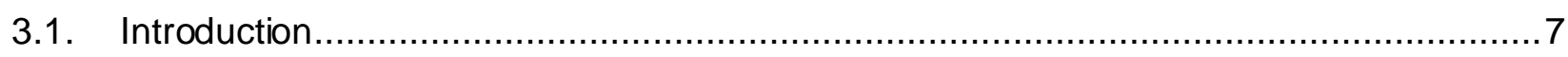

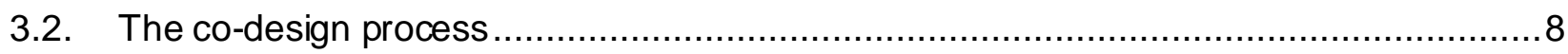

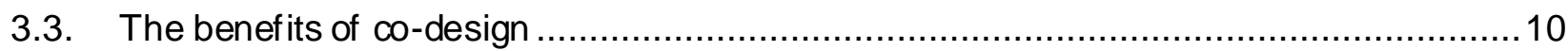

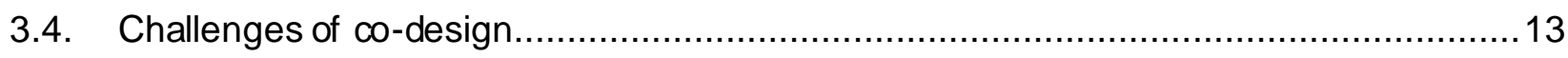

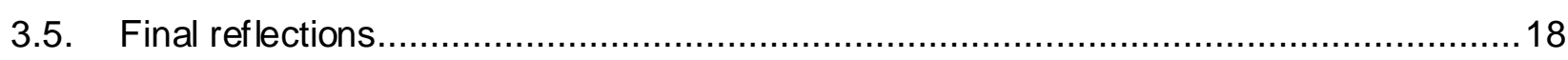

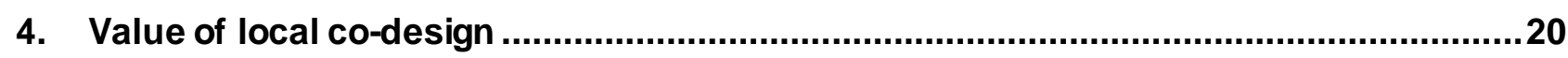

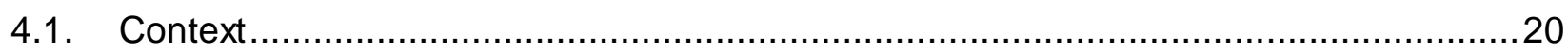

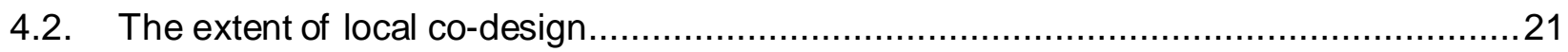

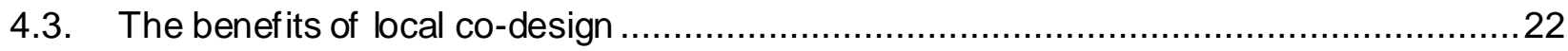

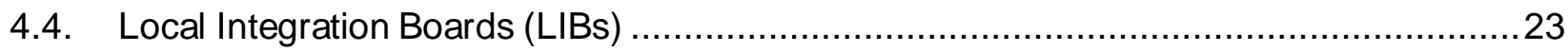

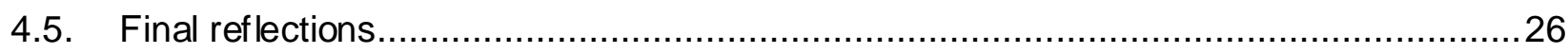

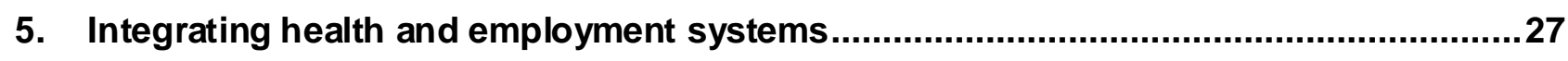

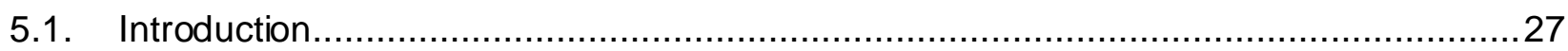

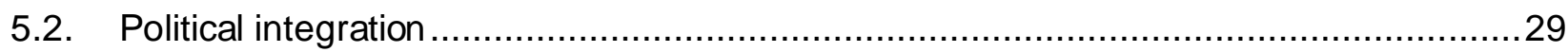

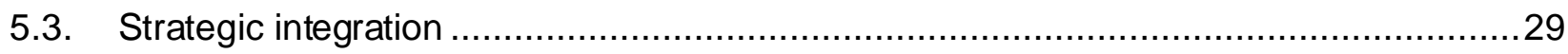

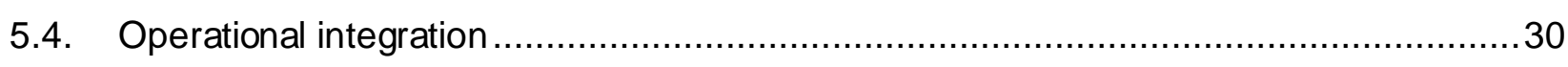

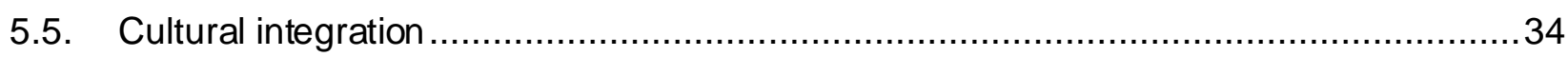

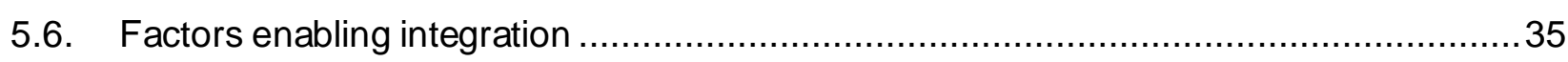

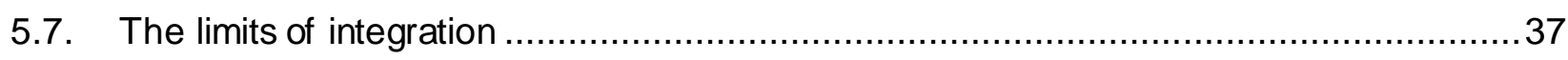

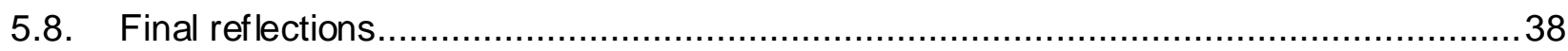


6. Lessons, legacy and opportunities

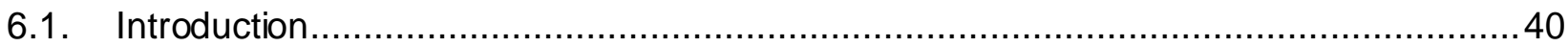

6.2. Lessons

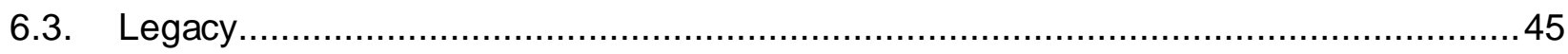

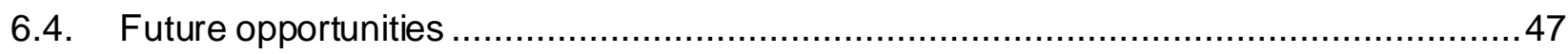




\section{Executive summary}

\section{Research aims and design}

- This study was commissioned by the Sheffield City Region mayoral combined authority (SCR) to understand the 'valued-added' of local co-design and partnership in the development, commissioning, implementation and delivery of WorkingWin. It has been led by a team from the Centre for Regional Economic and Social Research (CRESR) at Sheffield Hallam University.

- The primary aim of WorkingWin is to provide innovative and intensive employment support for people with mild to moderate health conditions to help them to remain in or find work. It is based on a modified Individual Placement and Support (IPS) model.

- This research is based on interviews and a workshop with 36 stakeholders from a range of organisations involved in some aspect of the WorkingWin including managing, codesigning, commissioning, delivering, or referring into the service. This includes the SCR Mayoral Combined Authority, local authorities as well as health professionals and clinicians from across the NHS and Integrated Care System (ICS).

\section{Co-design in WorkingWin}

- Co-design is a guiding principle of WorkingWin with local partners collaborating closely to design and develop all aspects of the programme from inception to de livery.

- Interviewees felt WorkingWin successfully engaged most key partners in the codesign process with a range of representation by organisational type, stakeholder expertise and geographic areas.

- The co-design process which was seen by many as inclusive process with genuine opportunties to shape WorkingWin. Benefits attributed to co-design included securing senior-level buy-in; building effective partnership working between health and employment partners; engaging clinical services and staff; developing referral pathways; providing NHS research expertise to support the trial; and tailoring design to local contexts and systems.

- While interviewees were largely positive about the co-design process, challenges were identified around the limited involvement of some frontline clinical health services expected to refer into WorkingWin. Greater involvement from professionals in clinical services at an earlier stage could have helped implement referral pathways sooner; brought more local partners on-board; smoothed co-location issues, particularly with MSK services; and helped address GDPR and data sharing issues. The absence of employers and voluntary and community sector partners was also noted.

- There were also issues identified with central government requirements, both in terms of the time pressures to get WorkingWin up and running and, in particular, the stipulation that the programme was delivered as a randomised control trial (RCT). This was seen to limit the time and scope for co-design activities and, in some cases, deter referrals. 


\section{The value of local co-design}

- One of the central aims of WorkingWin is to demonstrate the value of local co-design. This centres on the notion that interventions are more efficient and effective when they are able to tap into, and be responsive to, local contexts.

- There was a consensus that the WorkingWin was distinguished by, and benefited from, its local approach. Local co-design activities were considered to add value to WorkingWin by creating a shared sense of ownership and trust; enhancing the credibility of programme and commitment from partners; and harnessing pre-existing local infrastructure, networks and relationships to support implementation and delivery

- At the same time, it was recognised that differences at the outset in local infrastructure, relationships and cultures meant more work had to be done in some areas than other to secure the support and involvement of key health services. There were some concerns that the parameters set by delivering WorkingWin as an RCT limited its flexibility and sensitivity to local context.

- Local Integration Boards have been used to provide oversight and support the delivery of the programme in each of the five participating areas. They were seen to play an important role in developing local networks and relationships, identifying and responding to implementation and delivery issues locally, and driving integration of health and employment activities. However, there have also been issues including variable levels of commitment and effectiveness, a lack of clarity over purpose in some cases, and limited engagement of certain health partners.

\section{Integration of health and employment systems}

- Closer integration of health and employment systems is a key ambition of WorkingWin. At its heart is recognition that addressing health-related barriers to work requires engagement and delivery across multiple domains that encompasses not just employment and skills but also health as well as other policy areas.

- Overall, there was sense that integration had been successful in a number of ways including:

- political integration in terms of the buy-in of senior 'champions' within key organisations such as the ICS and CCGs who played an instrumental role in engaging clinical services and practitioners.

- $\quad$ strategic integration where senior stakeholders were signed up to the vision 'work as health outcome', particularly where WorkingWin aligned with national strategies and initiatives.

- operational integration in terms of generating referrals and co-locating WorkingWin Employment Specialists with frontline clinical services.

- cultural integration where services and clinicians experienced or implemented changes in values, practices and partnerships to support WorkingWin and the wider joint work-health agenda.

- The three health service pathways (GPS, IAPT and MSK) accounted for half (51 per cent) of all referrals. Some questioned the levels of engagement from some health partners, especially GPs, although variations seemed as much by individuals or practices within services rather than across services per se.

- Co-location was seen as an important element of service integration and was crucial in terms of fidelity to the IPS model. There were mixed views on the extent of integration achieved around co-location of Employment Specialists in clinical teams. On some sites there was no co-location at all, while on others there was valuable joint working between WorkingWin staff and health teams. 
- $\quad$ Co-location was felt to deliver a number of benefits including encouraging and discussing referrals, building partnerships, creating a feedback loop between frontline services and the Steering Group, and providing opportunities for clinical practitioners to get immediate responses to queries.

- Factors supporting closer integration of health and employment systems included: the energy invested by the SCR team and provider; the CCG-led procurement process; the positioning of WorkingWin as a health-led employment programme; the co-design process and senior strategic support in health organisations; NHS research expertise; peer advocacy and learning; and streamlining the referral process.

- Perhaps inevitably, there are limits to the nature and extent of integration, most notably where gaps in representation at the Steering Group. The absence of some individual CCGs as well as managers below Chief Executive level working more directly with frontline clinical teams was felt to lead to lower levels of engagement from some clinical teams in localities.

- Other factors constraining integration include delays in establishing the Trial in acute settings; the time-limited nature of the programme; challenges in engaging GPs; concerns about the RCT element; issues with data protection and information governance; and competition from other programmes.

- Overall, the level of health and employment system integration achieved should not underestimated given the challenges health-focussed employment support programmes have often facing in engaging health partners, particularly from within NHS clinical services.

\section{Learning and future opportunities}

- Wider lessons that emerge from the experiences of embedding co-design within WorkingWin for any successor programme include the need to:

- Ensure local areas take responsibility for driving cross-silo forms of delivery and governance.

- Identify and engage the full range of health partners required an early stage.

- Allow sufficient time and resource at the mobilisation phase to undertake engagement activities.

- $\quad$ Provide more support and guidance around the role and composition of LIBs.

- Bring in relevant NHS research expertise at the earliest possible stage.

- Encourage and train clinicians to see the value of, and embed, 'work as a health conversation' in their practice.

- Identifying champions within organisations who are able to promote WorkingWin.

- Recognise the importance of good communication and "using a language that everyone understands."

- The experience of WorkingWin raises questions about the appropriateness of an RCT for an employment support intervention given that the design was not completely experimental or untested, and other less contentious evaluation methodologies were available. Some felt it had deterred the engagement of clinical teams and lowered referral volumes, although others recognised its legitimacy as a research method given its potential to generate highly robust evidence.

- $\quad$ There was a clear view among stakeholders that WorkingWin had proved its value and many advocated for continuing the service in some form to sustain its legacy. Concerns were expressed that valuable local infrastructure in terms of networks and relationships developed around WorkingWin could fizzle out it if no successor vehicle were put in place. 
- Stakeholders provided a number of suggestions on what any future iteration of integrated health and employment support should look like in the SCR including:

- Building provision directly into local structures in terms of commissioning and delivery as part of mainstream services rather than being funded and implemented as a pilot initiative.

- Simplifying the complex and confusing landscape of employment support by having a limited number of employment support programmes with clear eligibility criteria.

- Rethinking the model as the high unit costs of the IPS model might not be sustainable if commissioned as mainstream provision.

- Using social prescribing programmes pathways as a potential point of triage into any future programme to streamline referral.

- Continuing and expanding training for health professions around employment as a social determinant of health to address existing 'gaps' in engagement and commitment from clinicians.

- Exploring the possibility of drawing down funding from a number of sources including future devolution agreements.

- Maintaining the co-ordinating role of the SCR in managing any future commissioning, implementation and delivery of joint work-health provision.

- Ensuring that the promotion and development of joint employment and health support is embedded with in key SCR strategies and initiatives 


\section{Introduction}

\subsection{Overview of HLET}

The Sheffield City Region Combined Authority (SCR) is working in partnership with the Department for Work and Pension's (DWP) and Department of Health and Social Care's (DHSC's) joint Work and Health Unit (WHU) to design and deliver a Health Led Employment Trail (HLET). The SCR HLET was launched in May 2018 and branded as WorkingWin with South Yorkshire Housing Association (SYHA) commissioned by SCR to provide the service. WorkingWin operates in five local authority and CCG areas: Barnsley, Bassetlaw, Doncaster, Rotherham and Sheffield. This programme is funded by NHS England, the Department of Work and Pensions (DWP), and the Department of Health (DH). It forms part of a national Innovation Fund programme to build the evidence for approaches that support people with health conditions and disabilities into paid employment.

The primary aim of WorkingWin is to provide innovative and intensive employment support for people with mild to moderate health conditions to help them to remain in or find work. It is based on a modified version of the well-evidenced Individual Placement and Support (IPS) model (see Section 1.2.). The programme is health-led as the main referral routes into the scheme are via three clinical services: GPs, Improving Access to Psychological Therapies (IAPT) and Musculoskeletal Services (MSK). WorkingWin Employment Specialists delivering the service are co-located within or provide services from primary and community NHS services in the region.

WorkingWin is run as a Randomised Control Trail (RCT). This is a scientific method frequently used in health research or drug trials and increasingly within employment programmes ${ }^{1}$. It measures the impact on outcomes among those who receive an intervention relative to a control group who have not received the intervention. The WorkingWin RCT has seen over 6,000 participants opt into the trial and then randomly allocated to either an intervention group (who receive supportfrom the programme) or the control group (who receive no support from the programme and instead rece ive 'service as usual'). The approximately 3,000 participants in the intervention group receive up to 12 months support from their point of entry onto the programme. WorkingWin opened for referrals in May 2018 and the last referrals were accepted in October 2019.

There is a separate HLET being delivered in the West Midlands Combined Authority (WMCA) called Thrive into Work. The model for the WMCA HLET is different as it only focuses on those who are out of work whereas WorkingWin includes both in -work and out-of-work cohorts. Both trials have been funded by, and co-designed with, the WHU

\footnotetext{
1 The Work and Health programme, for example is currently being delivered and evaluated through an RCT: https://www.gov.uk/government/publications/work-and-health-programme-statistics-background-information-andmethodology/work-and-health-progamme-statistics-background-information-and-methodology
} 
under the same framework of core principles, but use different local models of provision. This study only concerns SCR's WorkingWin and the WMCA is not part of this local evaluation.

\subsection{Individual Placement and Support Model}

WorkingWin is based on a modified Individual Placement and Support (IPS) model. The IPS model has previously been shown to work well with people with severe mental health issues ${ }^{2}$.WorkingWin explores whether a modified version of IPS will support people with less severe health issues to find or stay in work. The principal modifications froma 'traditional' IPS service being tested are outlined in Table 1 below:

Table 1: Modifications to IPS in Working Win model

\begin{tabular}{|l|l|l|}
\hline Element of model & 'Traditional' IPS model & Modifications in WorkingWin \\
\hline Condition & Mental health & Physical and mental health \\
\hline Severity of condition & Severe & Mild to moderate \\
\hline Cohorts & Out-of-work participants & In-work and out-of-work participants \\
\hline Volume & Small volumes & Larger volumes \\
\hline $\begin{array}{l}\text { Referral and } \\
\text { delivery setting }\end{array}$ & $\begin{array}{l}\text { Secondary community mental } \\
\text { health teams }\end{array}$ & $\begin{array}{l}\text { Primary care and secondary } \\
\text { community mental health teams }\end{array}$ \\
\hline
\end{tabular}

In SCR the Working Win model includes:

- 12 months of one-to-one employment support tailored to the needs and employment aspirations of the individual

- $\quad$ support to find paid employment and continued support once in work

- $\quad$ help to remain in work if a health condition makes this difficult

- $\quad$ employment advisors known as Employment Specialists working in partnership with health professionals

- $\quad$ benefits advice

- help for employers to support clients' needs at work

- meetings at a location which is convenient forthe client or support over the phone.

The model distinguishes itself from standard employment support provision with a 'place then train' approach, smaller caseloads (a maximum of 35), working to a strict modified IPS Fidelity scale, and support to integrate with local wraparound services via Local Integration Boards (LIBs) at local authority level.

While SYHA deliver the IPS model of employment support to beneficiaries within the trial, this occurs within a wider partnership involving a broader group of local stakeholders. Local partners involved with the design and implementation of the trial include:

- $\quad$ SCR and both Public Health and Employment and Skills teams within the five local authorities (Sheffield, Barnsley, Doncaster, Rotherham and Bassetlaw)

${ }^{2}$ Bond G, Drake, R, Becker, D (2008) An update on randomized controlled trials of evidence-based supported employment outside the US. World Psychiatry, 11 32-39. 
- $\quad$ wider health partnerships and commissioning groups: South Yorkshire and Bassetlaw Integrated Care System (ICS), Clinical Commissioning Groups (CCGs)

- Multi-agency Local Integration Boards (LIBs) led by local authorities

- clinical services: GPs, Improving Access to Psychological Therapies (IAPT), Musculoskeletal Services (MSK)

- $\quad$ voluntary and community sector partners including Zest and Manor and Castle Development Trust

- $\quad$ national partners: DWP, DHSC, WHU and NHS England.

WorkingWin is managed by the SCR while procurement was led by the Sheffield CCG on behalf of the five local CCGs within the trial. SCR, local authorities and wider health partners all played a key role in the co-design phase and were represented on the Steering Group responsible for design and implementation, as well as undertaking communication, consultation and co-ordination with local partners and LIBs. LIBs provide oversight and scrutiny of WorkingWin in the five delivery areas as well as any support needed to implement and deliver the programme. Clinical services provided referrals and worked as partners in providing integrated work-health support to service users including co-location with Employment Specialists. Voluntary and community sector partners also provided referrals and co-location opportunities for Employment Specialists. National partners funded WorkingWin and shaped some key parameters, particularly in terms of stipulating through an RCT. 


\section{Research design}

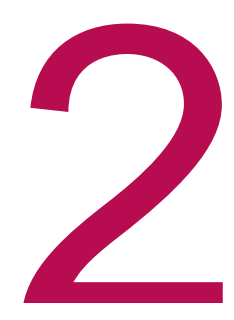

\subsection{Overview}

This study was commissioned to understand the 'valued-added' of local co-design and partnership in the development, commissioning, implementation and delivery of WorkingWin. It has been led by a team from the Centre for Regional Economic and Social Research (CRESR) at Sheffield Hallam University. This local evaluation supplements the national evaluation which covers both the SCR and WMCA trials. A key focus of the national evaluation is an impact evaluation of the outcomes of participants who received employment support relative to a randomly allocated group of participants who did not. The national evaluation is being undertaken by a consortium which is led by the Institute of Employment Studies. This local evaluation does not consider the experiences or outcomes of participants in the trial as this remains the focus of the national evaluation.

\subsection{Aims of the research}

This research is based on insights from partners to explore the local roles around, and value-added of, co-design at all stages of WorkingWin. It centres on qualitative research with a range of stakeholders that examined their perceptions and experience as to what worked well or not so well and lessons to take forward for future provision. The study seeks to address three key questions. These test the central proposition of WorkingWin that integrated employment and health support is most effective when developed collaboratively between key health and employment partners, and able to draw on local knowledge, expertise, networks and service infrastructure:

- How has co-design shaped WorkingWin and what are the benefits, if any, of a codesigned approach?

- What is the value of a local approach in the design, implementation, delivery and governance of an integrated work and heath programme?

- What are the lessons from, and legacy of, WorkingWin and how might these shape any future integrated health and employment provision in the SCR?

This research is based primarily on 25 in-depth qualitative interviews with a wide range of stakeholders involved in the design and delivery of WorkingWin across the five local authority areas. The study team also conducted a workshop in March 2020 to probe further around key themes from the research. This included some stakeholders who had already been interviewed as well as an additional 11 participants who had not previously taken part in the study. This means that, in total, $\mathbf{3 6}$ different stakeholders were consulted either through interviews or the workshop. 
Respondents include those involved in the commissioning process, the steering group, co-design of the service, referral pathways, implementation and provision of the service. Many respondents were involved in more than one of these aspects of the programme from the start of the programme but others have only been involved at certain stages of the process. Interviews and workshops included stakeholders from all key organisations, services and partnerships involved in the Programme: SCR, local authorities, ICS, CCGs, NHS services, SYHA and national partners.

\section{Interviews focussed on a range of themes including:}

- $\quad$ the co-design process;

- real-time feedback mechanisms to shape the implementation of the programme;

- $\quad$ referral pathways;

- $\quad$ partnership working;

- $\quad$ engagement of health professionals;

- co-location;

- the value of a local approach;

- $\quad$ wider governance structures (Local Integration Boards);

- $\quad k e y$ lessons from the programme;

- legacy of the programme;

- future opportunities for integrated health and employment provision.

Interviews with stakeholders lasted between 45 and 60 minutes and were digitally recorded. Detailed notes were taken from the recordings for approximately half of all interviews while the other half were transcribed in full where insights are particularly rich or detailed. The research team at CRESR mostly conducted the interviews by telephone and some were undertaken face-to-face. The data collected from interviews has been analysed to identify key emerging themes and issues.

The study has been approved by Sheffield Hallam University as fully compliant with its research ethics policy and procedures. This ensures that informed consent is gained from all participants taking part in the study and that all data is stored in adherence to strict data protection and privacy rules. All responses from participants are confidential, anonymised and not attributed to any individual respondent. Where quotes are used in this report a general descriptor is used to give an indication of the type of organisation that the interviewee belongs to. The only exception is for those taking part in workshops who are simply labelled 'stakeholder workshop' because of the difficulties in identifying roles and organisations from recordings of a group discussion.

Finally, it is important to note that all the research for this report was undertaken before the full extent of the COVID-19 pandemic became evident and the UK moved into lockdown on March $23^{\text {rd }} 2020$. Clearly, this will have significant implications for any future work around employment and health strategies against a rapidly emerging and unstable backdrop of a deep and possibly enduring recession; large rises in unemployment; the furloughing of a significant section of employees; on-going uncertainty and risks to many business; and a potential increase in mental health issues. It is beyond the scope of this report to comment on what the response to the crisis should be. However, it may provide valuable learning to support any joint health and work interventions put in place as part of any package of recovery measures. 


\subsection{Structure of the report}

The remainder of the report is structured as follows:

- Section 3 considers perceptions and experiences of co-design within WorkingWin. It explores the extent of co-design within the programme; how it shaped design, implementation and delivery; the benefits of a co-designed approach; and the challenges in adopting this approach.

- Section 4 examines the value of a local approach to co-design in terms of the nature and extent of local partners' involvement; the perceived benefits of local working; and the role and effectiveness of Local Integration Boards as mechanisms of local governance, scrutiny and support.

- Section 5 explores the integration of health and employment systems within WorkingWin. It focusses on the degree and benef its of integration across different dimensions of the programme; the factors enabling integration; and the limits of integration as a result of both internal and external constraints.

- Section 6 concludes by looking at the legacy of, and lessons learnt from, WorkingWin. It reflects on the appetite and perceived opportunities among stakeholders for developing further integrated health and employment provision in the future. 


\section{Co-design}

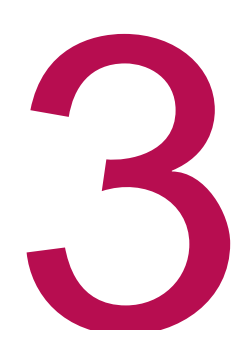

\subsection{Introduction}

Co-design is a guiding principle of WorkingWin with local partners collaborating closely to design and develop all aspects of the programme from inception to delivery. The co-design process included:

- $\quad$ the development of the initial bid with the Work and Health Unit to deliver a local Health-Led Employment Trial

- $\quad$ setting the aims and objectives of the programme

- deciding upon the governance inf rastructure and commissioning process

- identifying key referral routes and delivery mechanisms

- and suggesting real-time adjustments to the implementation of the programme to ensure that delivery was aligned to the original objectives set.

A co-designed approach was intended to enable flexibility and sensitivity to local context, priorities and services. At the same time WorkingWin also needed to adhere to the parameters set by WHU to operationalise an RCT that tested a modified version of IPS.

A range of multi-agency mechanisms were developed to facilitate co-design and ensure inclusion of local partners including an SCR-wide Steering Group (also known as the Co-Design group) and sub-groups, co-design workshops, and Local Integration Boards (LIBs). Local real-time feedback mechanisms allowed a range of partners to contribute to on-going adjustments to the design of the programme.

The inclusion of local stakeholders at all stages of design, implementation and delivery sought to add value by:

- drawing on the insights, experiences, networks and knowledge of local partners

- recognising the need to cut across traditional service and organisational boundaries as well as ways of working

- $\quad$ securing buy-in and engagement from key local partners

- $\quad$ maximising the effectiveness of the implementation and delivery of WorkingWin in different local contexts e.g. in developing referral pathways. 
A range of local and national partners were involved throughout the co-design process. This reflects wider national policy agendas such as the Improving Lives ${ }^{3}$ strategy which increasingly focus on the importance of taking a more holistic approach to work and health. Key partners included:

- $\quad$ The SCR Mayoral Combined Authority and Local Enterprise Partnership (LEP).

- Officers from a number of teams in all five local authorities including Public Health, Employment and Skills, Communications, and Strategy and Performance teams.

- Health professionals and clinicians from across the NHS and Integrated Care System (ICS) including those from primary and secondary care, and acute and mental health services. This included Clinical Commissioning Groups (CCGs); GPs, GP Practice Managers and GP federations; NHS service managers from Improving Access to Psychological Therapies (IAPT) and Musculoskeletal Services (MSK); and in some instances wider stakeholders engaged with local social prescribing.

- National partners from WHU were also integral to the process as were contributions from Jobcentre Plus.

Often, more than one team within partner organisations were involved at different stages of the process. For example, those contributing to the process from the SCR and Local Enterprise Partnership (LEP) included members of the executive, the LEP Board, and the employment and skills team.

The following section of the report examines the reflections of local stakeholders on their experience of various aspects of the co-design process. Questions focused on the extent to which they found the co-design process useful or not and the ways in which it had shaped the programme. Elements of the co-design approach explored in these interviews included the commissioning process, implementation of the programme, partnership working and referral pathways. Respondents were asked to comment on how their organisation had contributed to the process, the role of wider governance structures, and if any potentially important partners were missing from the process.

\subsection{The co-design process}

Many respondents had been actively involved with, and contributed to, different elements of the co-design process. For some, this was through formal mechanisms such as the Steering Group responsible for many of the initial aspects of co-designing the programme including:

- initial bidding to WHU to secure funding for trial

- developing the framework of aims and principles of the programme

- commissioning the provider

- designing the modified IPS fidelity scale

- identifying delivery sites and referral pathways

- developing and implementing co-location arrangements

${ }^{3}$ Department for Work and Pensions and Department of Health (2017) Improving Lives: Work, Health and Disability. Cm 9526, London:TSO 
- $\quad$ ensuring that relevant wider local stakeholders in their local areas were informed and engaged in the design of the trial

Steering Group activities evolved over time, beginning initially as intensive weekly twohour face-to-face meetings with local authority leads tasked with local engagement and problem solving between meetings. Meetings become less frequent or were held as teleconferences at later stages of implementation.

The composition of partners involved in the co-design process also changed over time. Some participants were involved from the start of the process and continued to shape the real-time development and implementation of the programme once it went live. Others provided input at specific stages of development or focused on particular aspects of project development or implementation. This included, for example, ensuring that ethical and information governance requirements were in place to enable the WorkingWin delivery team to operate in clinical settings.

Other respondents attended co-design workshops or became involved in sub-groups which evolved out of the Steering Group. These sub-groups often took the lead in specific elements of the programme such as implementation, developing referral pathways, and delivery of certain aspects of the programme (for example: Communications sub-group; Employment Services Support Group). Members of subgroups were often responsible for then communicating and resolving operational issues within their own organisations as well as with committees, partnerships or governance structures in their area.

A key question concerned the extent to which Working Win had engaged all the right partners in the co-design process in terms of an appropriate range of organisations and staff remits and seniority, as well as representation across the five Localities. Reflecting back, one stakeholder noted the challenge that engaging the full range of partners presented:

"The challenge was how do you get all those people around a table and design something that puts everyone's viewpoints in and where there are conflicting viewpoints, how do you deal with that?". SCR

It was clear that many interviewees felt WorkingWin successfully responded to that challenge by engaging all key stakeholders in the co-design process and achieving representation by organisational type, stakeholder expertise and geographic areas:

"You just see the relevant partners are represented there and how helpful that is... There was good engagement across organisations overall". Public Health

"I think we hit the main partners that needed to be there". SCR

"All the areas seemed to be represented and different CCGs". Public Health

"Just seeing the level of engagementby differentpartners and the degree to which they were being invited to work and shape how it was going to work did give me an insight into the fact that co-design was clearly going on." Public Health

It was often also noted by respondents that the variety of knowledge, experience and expertise brought to the co-design process had been beneficial to shaping the programme:

"It worked quite naturally that we all brought our skills rather than just represented a geographic area. I could speak about whether GPs would like it whoever they were. It worked well". CCG 
"It was about getting the right experts around the table, because, although we spoke to them all independently, it was kind of like pulling them all together into that co-design process". SCR

"Everybody had clear roles and everyone from the boroughs had clear responsibilities". Local Authority

\subsection{The benefits of co-design}

Interviewees were largely positive about their involvement in the co-design process which was seen by many as inclusive process with genuine opportunties to shape WorkingWin:

"It was a positive co-produced process...A lot of what we hoped would happen did happen to produce a co-produced bid". Public Health

"Really good, really positive...Everyone was fully engaged...it truly was a joint partnership approach to co-design". Local Authority

"We were trying to do a lot more with people rather than to people". SCR

A number of benefits of co-design were identified including its contribution towards:

- $\quad$ securing senior-level buy-in

- $\quad$ building effective partnership working

- $\quad$ securing engagement of clinical services and staff

- developing referral pathways

- $\quad$ providing NHS research expertise to support the RCT element of WorkingWin

- $\quad$ tailoring design to local contexts and systems (explored in detail in Section 4)

\subsubsection{Senior level buy-in}

The co-design process was seen by several respondents as playing a key role in securing strategic level buy-in from senior leaders in the NHS (including Trusts, CCGs and the ICS), the SCR Mayoral Combined Authority (including the Mayor), and local authorities. These "strategic senior endorsements" (Public Health) helped, in turn, to secure engagement of frontline clinical services (IAPT, mental health, MSK and GPs). This was particularly important at an earlier phase to boost lower than anticipated referral numbers:

"[There was a] mixture of a number of interventions [to boost referrals] so there was the high level 'Let's get the ICS to write to people. And what can we get the Mayor to say?' So that level of strategic senior endorsement ...to the lower operational level of which GPs have we got referring and which GPs aren't referring." Public Health

One respondent also noted that engagement from their CCG's Chief Executive and SCR Board meant the right people at appropriate levels of seniority were involved in the Steering Group. This in turn helped to engage the Director of Commissioning at the CCG and other key stakeholders at local workshops. However, another respondent froma NHS Trust noted that that while there was "fantastic"senior level buy-in at Chief Executive level within the ICS this did not always filter down to the staff within clinical services at local level (see Section 3.4). 


\subsubsection{Partnership building}

A key ambition of WorkingWin is to build and strengthen partnerships to support closer strategic integration across health and employment systems as the basis for delivering more effective employment support to individuals with health conditions.

Respondents frequently mentioned the importance of a co-designed approach in bringing together certain local partners 'at the table' to support the development and implementation of WorkingWin. Often this was in reference to its contribution towards creating new or strengthened partnerships between employment and health partners:

"There was a genuine acknowledgement from the City Region that they did need to work with professionals and partners that maybe they hadn't had such strong relationships with before". Public Health

"These are groups that we already work with, or we probably didn't work excessively with the ICS at the point at which we crafted the trial, and that's one of the plus points that's come out of it. But I think we already had existing relationships with all those people...but they're conversations that we had with people separately". SCR

"I think it [SCR Combined Authority] brings together health, work and welfare, economic strategy. And at the time [before WorkingWin] it didn't". NHS Trust

"We really were starting from quite a really basic level of understanding possibly between our partners, at a strategic level anyway, about the connections between work and health. And I think this trial gave us an opportunity to actually open up that conversation by saying this is a tangible piece of work that we are going to be co-designing and delivering together". Stakeholder Workshop

These partnerships were identified by some respondents as essential in ensuring engagement with, and buy-in from, health professionals; smoothing or unblocking referral pathways; and for facilitating closer working between employment and health systems. This enabled WorkingWin to provide a more integrated service than previous employment support programmes. One clinician noted, for example that there had previously been some highly effective examples of health-focussed employment support but these had not always been connected to GPs or MSK teams.

Joint working was also credited with ensuring an effective commissioning process: "Commissioning worked really well"(Local Authority). While the SCR were responsible for overall management of WorkingWin, the Sheffield CCG's procurement structures were used as this enabled the programme to be classified as a health project. This made it easier to put data and information governance processes in place and secure access to NHS sites for Employment Specialists. A range of partners were involved both in the decision to procure the contract in five lots (one for each CCG area) and the scoring of bids. Interviewees noted that joint decision making around the choice of provider led to an enhanced sense of ownership among partners

\subsubsection{Securing engagement of local health services}

The involvement of health organisations and senior health professionals in the codesign process was regarded as crucial, in turn, to securing the engagement of frontline services and staff vital to implementing and delivering WorkingWin:

"We got much more buy-in [because of co-design]". Public Health 
"Made sense to have CCG involved as GPs central to the programme and needed a way of securing their buy-in, engagement and referrals". CCG

"Why would health professionals take public sector, LA workers seriously when we say we've got this great programme. The fact it had the NHS branding ... a strong relationship with the ICS. I think all were absolutely essential ingredients in the partnership to make it work". (SCR)

Key to this was the role of members of the Steering Group who could act as 'connectors' to engage local partners using their contacts and networks:

"It's that connectivity across Sheffield City Region but also the opportunity to localise". Stakeholder Workshop

"Having the local mix of people going round and making sure there was connectivity and the flexibility to do what you need at place was very very good.".

(Public Health)

One member of the Steering Group explained, for example how they used their role to engage key local stakeholders, particularly those with a commissioning role in NHS trusts (both acute and mental health) and the CCG. Securing buy-in from commissioners ensured that they, in turn, were willing to communicate the potential benefits of WorkingWin to the services they commissioned.

Crucially, co-design was seen to have built in the structures and opportunities for engagement activities to facilitate implementation and delivery of Working Win. For example, workshops or one-to-one discussions were held with local health professionals in each local authority to raise awareness of WorkingWin and to understand their requirements and preferences for getting involved. This was perceived to enhance and streamline key aspects of the programme including referral pathways and data collection systems.

\subsubsection{Referral pathways}

Developing effective referral pathways from clinical services into WorkingWin is key to its ambitions around integration. A number of interviewees noted the critical role played by CCGs in particular in the co-design process in terms of getting GPs and Practice Managers to engage with the trial and working with them to implement referral mechanisms and encourage referrals. The CCGs' involvement in the co-design process was also mentioned in the context of developing referral pathways with local IAPT services.

The involvement of CCGs and other key health partners including the ICS, NHS Trusts and public health teams supported the development of referral pathways in four main ways:

- Raising awareness of the potential challenges of engaging GPs in the programme at an early stage and highlighting the need to dedicate time and resource to securing their buy-in:

"[The Steering Group] got the message that it wasn't automatically go ing to be easy to engage with GPs and that they needed to work really hard on that and take advice from people who had been working with GPs for a long time ....particularly from colleagues in the CCG ". Public Health

- Communicating the aims of WorkingWin to local clinical services and professionals to secure buy-in and encourage referrals: 
"We made sure that comms, chief execs' letters...encouraged referrals and so on." NHS Trust

- $\quad$ Setting up an iterative feedback mechanism where health partners on the Steering Group could provide insights into potential blockages and solutions regarding referral pathways based on local conversations with GPs and clinicians.

- Supporting the implementation of co-location and joint working arrangements within NHS settings.

The fact that WorkingWin eventually achieved referral targets was seen as evidence that the co-design process facilitated by the Steering group and sub-groups played a key role in developing referral pathways:

"I think that the proof is in the numbers, the numbers are the sign that they did get good engagement from the referrers". Public Health

"[Co-design was] really useful in the beginning... helped to kick-start the referrals". SCR

\subsubsection{NHS research expertise}

Some respondents suggested that the complex procedures and significant time involved in running WorkingWin as an RCT with NHS partners was perhaps underestimated initially, particularly in terms of adhering to strict medical ethics and data collection. It proved critical therefore, and demonstrated the value of co-design, when local NHS partners were able to provide staff with the experience and expertise to support technical aspects of the RCT required to implement the Trail and secure ethical approval from the Health Research Authority. This included mapping data and information government flows; undertaking capacity and capability checks to ensure clinical teams could refer into and support WorkingWin; and securing NHS passports to enable Employment Specialists to co-locate with NHS teams. One interviewee noted that some of this is standard practice in clinical trials but had not been embedded into the initial design of WorkingWin.

With hindsight, one interviewee felt it would have been beneficial to engage NHS staff with research and information governance expertise earlier. Another respondent from a local health trust noted that the lack of initial expertise led to delays in referrals:

"I mean, I know for [one] Hospital it took ages because, again, because of the $R \& D$ piece [i.e. getting the ethics requirements and practical procedures all sorted]... they were slow to get started...physios were really keen but...they couldn't get going". NHS Trust

This highlights the point that co-design on a programme like WorkingWin requires identification and involvement of both public and clinical health services and teams at all appropriate stages. A consistent lesson is the need to recognise that local authoritybased health expertise alone is not sufficient to run a trial of this kind.

\subsection{Challenges of co-design}

While interviewees were largely positive about the co-design process, challenges were identified around the limited involvement of key partners. This mostly concerned clinical health services although the absence of employers and voluntary and community sector partners was also noted. Some interviewees also highlighted the difficulties posed by the requirement that WorkingWin be delivered as an RCT. 


\subsubsection{Involving key partners}

A key challenge identified by the respondents for ensuring effective co-design was getting the right people involved at the right stages of the process. As noted above, while many were largely positive about the range of stakeholders engaged in codesign there was also a view, especially among health professionals, that some clinical health services could have been more involved at an earlier phase. Some respondents observed, for example, that health organisations and services expected to support Working Win and provide referrals could have been engaged sooner or more fully:

"You need to have those NHS organisations around the table.... It was great to have commissioners involved but you also need those people who are involved in delivery. There was no [name of] Hospital, there was no [name of] Hospital [where MSK teams are based] yet there was an expectation that there would be high levels of referrals from those organisations". NHS Trust

"If you think about where the referrals into the trial came from, so mental health trust, GPs, primary care, those sorts of groups, and even people themselves as self-referrers, they weren't involved in the co-design". Public Health

"Not so sure Trust-wide that the right people were there to ensure a buy-in into the programme...We were keen to have the programme to work with and so we were already sold on the idea whereas I'm not sure that other aspects of the Trust were..I think there needs to be more ground floor management involved in it. It felt a bit like higher management were agreeing to it whereas you needed buy-in from Team Managers as that is where referrals come from"IAPT

As another interviewee reflected, early co-design and engagement activity focussed too much on securing senior level buy-in without sufficient attention to "how it could be delivered in a NHS setting and what the barriers and facilitators are to that on a practical level" (CCG).

This view was not universal, however, with other interviewees highlighting the engagement work that had taken place with frontline NHS services and staff. Senior stakeholders on the Steering Group were seen as 'connectors' responsible for cascading information to frontline services and channelling information back. This was formalised with local authorities each nominating a lead on the Steering Group with a designated role to communicate with, and feed back from, clinical service leads. It clearly worked in some cases, as one service lead explained:

"Before the trial started I was involved with discussions with [a Local Authority representative] who brought it to us and said how can we get your MSK patients, if appropriate, part of this. And so we had a discussion about how we could make that work. What rooms, for example, if we could co-locate some of the Working Win team with our MSK team and how could we make that happen". MSK

'On the ground' conversations between clinical staff and Employment Specialists once the programme went live also enabled frontline teams referring into WorkingWin to identify issues and potential adjustments in 'real time'.

The divergent views on the extent to which clinical teams were part of the co-design process may reflect a number of factors. It could include the vantage point of individual stakeholders and the extent of their direct involvement in, and knowledge of, the codesign process. It may also be function of local variations in the degree to which clinical leads within any particular clinical service chose to engage with WorkingWin. 
Either way, it seems clear that mechanisms and processes were put in place to facilitate the engagement of clinical leads and teams in co-design, but this may not always have happened to the degree intended. Ultimately, as one interviewee reflected, there wasn't as much communication and "two-way influence" (NHS Trust) in the design process as there could have been between the Programme and health organisations.

The perceived lack of engagement from some clinical services in the design and implementation phase was seen to have a number of implications. Some perceived that greater involvement from professionals in clinical services at an earlier stage could have helped implement referral pathways sooner; brought more local partners onboard; smoothed co-location issues, particularly with MSK services; and helped address GDPR and data sharing issues. In some Localities, the lack of early involvement from clinical services was felt to have directly contributed to delays in generating referrals that required the Provider to undertake more engagement work than might otherwise been necessary.

In terms of reasons for the lack of early involvement in co-design of some clinical services, one respondent noted it may in part have been due to the ICS not being fully established at the beginning of the design process, with roles and resources only becoming clear later on. Other interviewees suggested that the initial co-design process had focused too much on engaging senior public health professionals within local authorities rather than frontline clinicians or their patients:

"So we didn't have any sort of experts by experience as part of the co-design, you know, in the steering group...There've been managers of those services or, at worst, people like me who sort of have got a health background and are used as a sort of conduit into the health service but aren't actually sitting in the health service". Public Health

"I think that it was a bit too health-commissioner-led... A bit too public [health]. So, again, Sheffield City Region and DWP not realising that when somebody from public health attends a meeting, that does not mean NHS provider...GPs hadn't been fully involved, I don't think, early on... And certainly, the mental health trusts hadn't been involved". NHS Trust

However, the respondent went on to say that this situation had been rectified and the right clinical services and professions were involved by the time of programme launch: "And we quickly rectified it but, yes, I think there was a bit of a disconnect". (NHS Trust).

Key learning identified around involving health services partners is that engagement work is time-consuming and needs to be resourced accordingly. This includes sufficient time for conversations with partners before the programme goes lives:

"I would have expected some of those doors to have been pre-opened ready for the Provider to go in. It put them in a more difficult position". NHS Trust

"Maybe it wasn't appreciated how, you know, the time and energy it takes to really coproduce things and allow people to... to get buy-in". Public Health

Finally, all of the respondents were asked about the engagement of employers and the voluntary and community sector (VCS) in the co-design process. None of the interviewees spoken to were aware of involvement from either these partners at the early stages of co-design: 
"I think that is a lesson to learn, how do you involve [employers] at that stage?". Public Health

"I think the LEP board - it was more we'll let the local economic parties know about it... And it was sort of one of their workstreams but they weren't necessa rily in the room as employers...l think that was more left to the sort of local implementation". Public Health

"They [the VCS] will get updates on the trial, but in terms of influencing how the trial works, or feeding back in a systematic way, we probably haven't done that so well". SCR

Engagement work seemed more evident once WorkingWin had been launched, with the Provider working with the VCS to generate referrals and, in some instances, colocating with VCS services.

\subsubsection{National constraints on local co-design}

Respondents involved in the Steering Group were largely positive about the co-design process which was seen to engage a range of partners and provide genuine opportunities for them to contribute towards the design, implementation and delivery of WorkingWin. At the same time, it was recognised that there were challenges in codesigning a programme locally where some parameters had been determined a national level by the Work and Health Unit (WHU) as the funder.

Broadly, the involvement of the WHU was seen in a positive light and the SCR was considered to manage the relationship well. It was noted that compromise was sometimes necessary to achieve a programme that met both local and national needs but, ultimately, this had been beneficial to the final model developed without co-design becoming tokenistic:

"When you start working with Department of Health and DWP it got reshaped but I think if we hadn't had that co-produced model you probably wouldn't have such a good bid in the first place". Public Health

"We had some steer to it, but within tight parameters. I don't think it was just ticking the boxes though". CCG

There were issues identified with central government involvement, however, both in terms of the time pressures to get WorkingWin up and running and, in particular, the stipulation that the programme was delivered as a randomised control trial (RCT). This had implications for the co-designed approach underpinning the programme.

Looking firstly at time pressures at the mobilisation phase, some interviewees suggested that WHU expectations around the timetable for delivery meant that some of the technical issues had not been resolved by the go-live point. It was also suggested that the programme was launched before it had undertaken all co-design work necessary. This limited the involvement of key local health partners (see also discussion above):

"The high-level model, was sort of coproduced. The challenge then was implementing it... it was difficult then to sort of truly sort of coproduce it in four (sic) localities up against a sort of clock that was ticking in terms of getting it up and running". Public Health

Second, and perhaps more significantly, some respondents described certain elements of the programme as pre-determined "red lines" (Public health) that could not be crossed. The key area where it was perceived there was no flexibility in 
programme design was the requirement of funding to deliver it as a Randomised Control Trial (RCT):

"There wasn't true coproduction in that. There were some sort of red lines, particularly in terms of the trial methodology or how it was going to be implemented that actually made it more...difficult." Public Health

\section{"The tail wagged the dog". Local Authority}

One interviewee noted that being an RCT created concerns around securing strategic level buy-in from senior stakeholders as it was anticipated that it would be "politically sensitive" (Local Authority) for some. However, the partnership approach across the city region helped address this as partners could point to other areas and organisations who had already accepted the RCT to reassure local senior decision makers: "It was a hurdle we had to jump through". (Local Authority).

There were, however, a variety of views from respondents on whether working within the constraints of an RCT remained an issue once the trial went live. Some expressed ethical concerns about the control group being denied access to potential valuable support. There was also a view that it may have deterred referrals from clinicians:

"It did cause some anxiety with frontline staff that were likely to be making referrals. I think that they thought why would we bother to do this when some people might not even get anything". Public Health

"My predecessor had terrible stories of people who really, really were way back on their journey and really encouraged to go forward for the trial and then put in the control group. It being a trial did not increase referrals, did not help". Public Health

Another view expressed by a small number of interviewees was that IPS as an internationally proven model did not need to be delivered within an RCT that as more appropriate for experimental and untried interventions:

"IPS as a modality, when people have looked at it people were convinced that that probably ought to just be a policy option that we should have been using routinely rather than trialling it... So there was a sort of a concern that referrers may have a sort of ethical dilemma if they believe so strongly that IPS works". Public Health

However, it also has to be taken into account that WorkingWin was trialling a significant and as yet untested modification of the IPS model which could be seen to validate its rigorous evaluation.

Indeed, other interviewees considered the RCT a legitimate research method to collect robust evidence on whether the model worked. This was particularly the case with clinicians with experience of being involved in clinical trials as part of their professional work:

"These GPs believed in research and they understood it". Stakeholder Workshop

"Part of our role at this level is to evaluate effectiveness of service so we are open to research findings... I don't get the sense that it would put a lot of people off, certainly not within [our] services. We are generally quite aware of and amenable to literature and evidence that is out there". MSK 
There was also a view that some organisations perhaps lacked the "research literacy" (Public Health) to understand that the control group still had access to what one interviewee described as the "best of the standard offer for employment support" (CCG), including a specially commissioned service directory provided to every control group member:

"So, again, from a local authority perspective, there was a worry that some people thought if you were randomised to receive nothing you've got absolutely nothing... Whereas what you got was the standard offer...some of us in a sort of steering group, you know, have done these sorts of trials before and been involved in research, we probably underestimated the research literacy in the rest of our organisations". Public Health

\section{" [VCS partners] just didn't get the point of it as a research trial". CCG}

Despite concerns raised about the RCT, many stakeholders felt that the co-design process at the local level had still ensured the final model contained most of the elements they wanted and that there were genuine opportunities to shape WorkingWin:

"The work evolved and certain things happened like we had the RCT...which wasn't our original vision. But a lot of what we hoped would happen did happen to produce a co-produced bid". Public Health

Fulfilling the requirement to run WorkingWin as an RCT was also considered a worthwhile trade-off given the value of being able to draw down WHU funding to deliver the service: "[lt was a ] a great opportunity to work with the Work and Health Unit to bring additional resource into the city region to do this". Public Health

\subsection{Final reflections}

Co-design is a guiding principle of WorkingWin with local partners collaborating closely to design and develop all aspects of the programme from inception to delivery. It is clear that WorkingWin successfully engaged most key partners in the co-design process with a range of representation by organisational type, stakeholder expertise and geographic areas. The co-design process which was seen by most as an inclusive process with genuine opportunities to shape WorkingWin. Benefits attributed to co-design included securing senior-level buy-in, building effective partnership working between health and employment partners, engaging clinical services and staff, developing referral pathways, providing NHS research expertise to support the trial, and tailoring design to local contexts and systems.

However, challenges were identified around the limited involvement of some frontline clinical health services expected to refer into WorkingWin. The absence of employers and voluntary and community sector partners was also noted. Other issues were identified around central government requirements, both in terms of the time pressures to get WorkingWin up and running and, in particular, the stipulation that the programme was delivered as a randomised control trial (RCT). It was also felt it would have been beneficial to engage NHS staff with research and information governance expertise earlier.

These findings emphasise the point that co-design on a programme like WorkingWin requires identification and involvement of all appropriate public and clinical health services or teams at all appropriate stages. A consistent lesson within this is the need to recognise that local authority-based health expertise alone is not sufficient for a trial of this kind. It is important to stress that mechanisms and processes were put in place to facilitate the engagement of clinical leads and teams in co-design in 
particular, but this may not always have happened to the degree intended. This provides important learning for any future successor programme in terms of the need to continually review and improve engagement processes. 


\section{Value of local co-design}

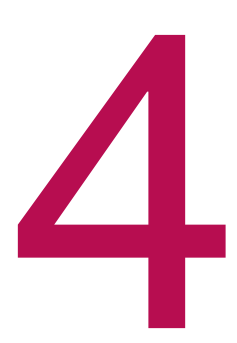

\subsection{Context}

WorkingWin has been funded by the Work and Health Unit which set key parameters around adherence to a (modified) IPS model and evaluating its effectiveness via the use of a Randomised Control Trial (RCT). At the same time, one of the central aims of WorkingWin is to demonstrate the value of local co-design in the development, implementation, delivery and governance of a locally integrated work and heath programme. This centres on the notion that interventions are more efficient and effective when they are able to tap into, and be responsive to, local contexts.

Potential benefits of local programmes include a greater sense of ownership among, and buy-in from, local partners; speedier and more effective implementation of the programme; the ability to harness existing networks e.g. to generate referrals; better understanding of the range of beneficiaries' needs and ability to work across service and organisational boundaries to address these; and enhanced scrutiny and problemsolving capability through local governance structures. A local approach is seen to avoid some of the pitf alls of centrally designed and implemented programmes such as 'parachuting' in Providers with limited knowledge of, or relationships with, local services.

WorkingWin intended to operate as a locally co-designed programme in in two key ways. First, embedding co-design as a guiding principle facilitates and empowers local partnerships to shape the design, implementation, delivery and governance of the programme at both the city-regional and district level. This occurs through both formal multi-agency mechanisms including the SCR-wide Steering Group and subgroups, and within local authorities through Local Integration Boards (LIBs) or equivalent vehicles. LIBs are intended to play a key role as a mechanism for facilitating partnership, sourcing referrals and smoothing local implementation. Initial consultation workshops and on-going meetings between the Programme team, provider and partner agencies as well as ad-hoc activities such as employer engagement events also provide scope for local involvement.

Second, WorkingWin seeks to draw upon and develop existing local infrastructure including expertise, knowledge, networks and services to facilitate quicker or more effective and efficient modes of integrated working across the employment and health agendas. This can include, for example, developing joint communications, co-location opportunities or referral pathways.

This section draws on interviews with stakeholders to explore two key themes in relation to the local features of the WorkingWin: the extent of local co-design and the perceived benefits of this approach; and the role and effectiveness of LIBs as mechanisms of local scrutiny of, and support to, the programme. 


\subsection{The extent of local co-design}

Interviewees were asked to reflect upon the extent to which the WorkingWin had felt like a genuinely local approach to co-design where local partners had been able to contribute to the development and implementation of the programme. There was a consensus that the WorkingWin was distinguished by, and benefited from, its local approach:

"It felt more local than a national trial". SCR

"It felt like the City Region was choosing to do something, not something that was imposed". SCR

"It was ours. We felt responsible. We were the owners of making this happen. We were relying on each other to see it through. From submission, specification, awarding the contract, delivery. It was us. We were it. I think that it gave us a strong commitment". Stakeholder Workshop

Several participants at the stakeholder workshop highlighted that the local co-design process had been an essential component of the programme as service provision was not uniform across the five local authorities. Partnership working within and across the five delivery areas ensured referral pathways were fit for purpose and tailored to the variety of local service providers.

There were some caveats about the extent of local co-design in WorkingWin. As already discussed in Section 3, there was a perception among some interviewees that some clinical health services had not fully engaged with the co-design process. Moreover, there were concerns that the parameters set by delivering WorkingWin as an RCT limited its flexibility and sensitivity to local context.

Some interviewees also discussed the implications for local co-design of commissioning a single provider to deliver in all five contract areas. On the one hand, the commissioning process was considered a valuable part of co-design, with a range of partners across the five localities assessing and scoring bids. On the other hand, some stakeholders suggested that tendering the contract in five lots had not led, as anticipated, to a range of providers being contracted according to their level of knowledge, experience, networks and embeddedness in localities:

"South Yorkshire Housing Association were successful in bidding across all five areas. So there are some lessons learnt from us there in the way we did that...So if you could answer the question well in one area [lot] you could get it in all of them. But I wouldn't do it that way [again]". SCR

"[The provider was] parachuted in and it didn't feellike it was owned locally". CCG

However, there was a view that, on balance, this did not necessarily matter as the provider was effective, well-regarded and had been able to tailor the service to localities. There were also distinct advantages in terms of consistency of service and economies of scale in using a single Provider:

"The benefit of having a single provider is it's very clear who's working and the team on the ground are really viewed very well". SCR

"It wasn't as local as it could have been but you also have to think economies of scale. It was done about the right level". CCG 


\subsection{The benefits of local co-design}

Interviewees were asked to reflect on the 'value-added', if any, of developing and implementing WorkingWin through a local partnership approach. There was strong consensus that the programme did benefit from a locally co-designed model in a number of ways including:

- Creating a shared sense of ownership and trust: Having "skin in the game" (ICS) not only secured initial buy-in from partners but maintained on-going commitment and investment in making the programme work:

"We were it. I think that it gave us a strong commitment". SCR

"If a programme is just dropped on the city, people don't take responsibility and ownership as they have got plenty of other things that are top of the list. But as a system if we are saying this is a priority for us in the City Region then it helps it happen". SCR

This sense of ownership and mutual responsibility was vital for a programme that needs to cut across service domains and organisational boundaries to provide wholeperson support:

"It is such a complex programme to deliver across...sectors...that if partners hadn't been brought round to having that sense of responsibility it wouldn't have worked". SCR

- Enhancing the credibility of programme and, by extension, the commitment of partners as it draws on local knowledge and expertise to a greater extent than centrally-designed interventions:

"If they had just gone 'here it is' it just wouldn't have worked." Public Health

- Tapping into existing local service infrastructure to ensure quicker and more effective implementation of WorkingWin. Buy-in, referrals and implementation such as co-location arrangements were all secured sooner because of trust, relationships and networks which could be harnessed:

"You are not at all starting from scratch, you're tapping into a vine where you graft something on the vine... that means it's going to work as you've got that existing level of trust...it would never have worked if there hadn't been existing relationships. It wouldn't have been quick enough". SCR

"You are tapping into someone in the CCGs who already has great relationships, great networks, great routes with GPs to persuade them". Public Health

"A lot of people involved in the Troubled Families initiative...they'd already got good networks and they were used to identifying eligible people and referring in". Public Health

- A local approach made it easier to develop and implement technical solutions necessary to make the programme work. For instance, creating a common referral process across the different IT platforms used by local GPS (EMIS and System One) was simpler to co-ordinate locally. A national programme may have been less agile in responding to local IT challenges. 
While there were a number of benefits associated with local co-design, some interviewees also noted that pre-existing variations in local inf rastructure, relationships and cultures meant more work had to be in some areas than other to secure the support and involvement of key health services, particularly GPs:

'[One area's] CCG generally has a good relationship with its GP practices...So they said 'if the CCG says it is OK then it is then'. Whereas in other places that's maybe not that strong a relationship or the CCG weren't saying it as strongly". Public Health

"The fact that some of the key system players were Sheffield-based meant it was good for Sheffield. I don't know if [other areas] had the same relationships with the...local authority or CCGs... I suspect we were on the front foot because of the relationships. I think [in other areas... a lot more work was having to be done with GPs". NHS Trust

\subsection{Local Integration Boards (LIBs)}

A key feature of the local co-design approach within the WorkingWin has been the use of Local Integration Boards or equivalent governance mechanisms to provide oversight and support the delivery of the programme in each of the five participating areas. These LIBs were intended to perform a range of functions including engaging key local partners, sourcing referrals, securing access to wraparound support for WorkingWin service users, monitoring performance, identifying and unblocking system-level and operational barriers, and exploring the legacy of the programme.

Each local authority area took its own approach to developing LIBs as outlined in Table 2 below:

\section{Table 2: The structure and composition of LIBs}

\begin{tabular}{|l|l|}
\hline Doncaster & $\begin{array}{l}\text { The LIB was specifically set up to oversee WorkingWin but was developed on the } \\
\text { back of a pre-existing multi-agency board responsible for the Stronger Families } \\
\text { prog ramme. Key agencies attending the LIB include the Stronger Families } \\
\text { prog ramme, Doncaster Council (including the Public Health team), JCP/DWP, Further } \\
\text { Education, Chamber of Commerce, all contracted employment provision, Business } \\
\text { Doncaster, Ledger Homes (an ALMO) and key health services (MSK, IAPT and } \\
\text { RD ASH (Mental health trust)). Over time the LIB has come to support a wider range of } \\
\text { programmes beyond WorkingWin and Stronger Families including Better Working } \\
\text { Futures, ESF provision and Doncaster Advance. }\end{array}$ \\
\hline Rotherham & $\begin{array}{l}\text { The LIB was originally set up in 2016 to oversee the Local Integration Plan and was } \\
\text { expanded to include WorkingWin. Agencies represented on the LIB include } \\
\text { Rotherham Council, CCGs, JCP/DWP, Troubled Families programme, Reed in } \\
\text { Partnership, SYHA, TRFT (Local Health Trust), RDASH (Mental health trust), and } \\
\text { Rotherham College. It was originally planned that the LIB would look at specific cases } \\
\text { to identity and resolve system-level issues but this role proved limited as many of } \\
\text { these issues were resolved by partners outside the LIB. The LIB was eventually split } \\
\text { into two different boards with separate strategic and operational responsibilities. }\end{array}$ \\
\hline Sheffield & $\begin{array}{l}\text { A LIB was set up in Sheffield but was considered to lack a clear operational focus and } \\
\text { was superseded by its more operationally focussed sub-group known as the } \\
\text { Employment Services Support Group (EESG). Member organisations currently } \\
\text { comprise Sheffield City Council including colleagues from skills and employability } \\
\text { teams, DWP, CCGs, Accountable Care Partnerships, and the Sheffield Health and } \\
\text { Social Care Trust. The EESG liaises with the Programme team and Steering Group } \\
\text { and seeks to resolve operational issues. }\end{array}$ \\
\hline Barnsley & $\begin{array}{l}\text { The More and Better Jobs Board created before the trial has been adopted as the } \\
\text { mechanism for overseeing WorkingWin. A key role of the More and Better Jobs Board } \\
\text { is to make links with employers. Membership includes a secondary school, FE }\end{array}$ \\
\hline
\end{tabular}




\begin{tabular}{|l|l|}
\hline & $\begin{array}{l}\text { college, NHS providers, community and voluntary sector organisations, employers } \\
\text { and employment support providers. The More and Better Jobs Board has an } \\
\text { Employer Promise to sign up businesses to help promote opportunities, and this has } \\
\text { been used as a platform to promote the Trial. }\end{array}$ \\
\hline Bassetlaw & $\begin{array}{l}\text { Bassetlaw has an Integrated Care System Board which has been used to discuss the } \\
\text { WorkingWin programme on an ad-hoc basis. However, it has no dedicated } \\
\text { mechanism for overseeing WorkingWin. }\end{array}$ \\
\hline
\end{tabular}

While the structure and function of the LIBs varies by area, there have been some common developments. Chief among these is the evolution of the LIB into more of an operational than a strategic vehicle. Expectations that LIBs could work to resolve system-level issues drawing on specific cases did not materialise for a number of reasons. This included the SCR-wide Steering Group taking on this function, the lack of difficult cases presented to LIBs, and the tendency of agencies to resolve systems issues outside of LIBs. Consequently, case conferencing and escalation of issues for resolution to a strategic level was limited.

\subsubsection{Key benefits of LIBS}

Interviewees felt that LIBs performed a number of useful functions that underscored the value of a local approach. In broad terms they ensured the programme remained focussed on, and tailored to local contexts:

"For this particular programme and the fact that the needs of participants in local authorities vary so differently, in the different geographies, it brings back that local flavour of we're very community based in terms of delivery of the trial and that's reflective of what those communities need". SCR

This illustrate how the 'double devolution' of governance and operational responsibilities from a city regional programme to local boards can deepen its embeddedness within, and responsiveness to, local contexts.

Specific benefits of LIBs identified included providing a forum to:

- $\quad$ develop local networks and relationships, particularly with health partners. This has direct benefits such as sharing information and learning as well as generating referrals. In Doncaster, for example, the attendance of NHS organisations on the LIB helped broker strong links with the teaching hospital and GPs which supported the development of referral pathways. LIBs also encouraged referrals from a wider range of partners beyond the 'usual suspects':

'"The referral partners that have been referring into the programme...have been probably much more diverse than otherwise would have been...Through LIBs you've got people like the 'Troubled Families unit' feeding in, other areas that you wouldn't traditionally think of as a referral agency, referring into the trial". Public Health

- identify and respond to issues within each of the five delivery areas:

"We use them quite a lot in terms of, outside of the steering groups, they do bring very, kind of local, partners and stakeholders [and] identify to us local issues that are happening". SCR

This included, for example, resolving operational blockages such as referral agencies simply informing clients about the service rather than making direct referrals. 
- drive integration of health and employment activities. For example, the More and Better Jobs Board which functioned as the LIB in Barnsley incorporated health objectives more closely into its remit around employment as result of its involvement with WorkingWin. This led it to promote WorkingWin as part of its Employer Promise and wider engagement work with employers.

\subsubsection{Key challenges around LIBS}

At the same time, stakeholders highlighted issues related to the functioning of LIBs that, at times, seemed to constrain their potential to engage a wide range of partners and support integrated forms of working. Key challenges identified included:

- a lack of clarity over the role and purpose of LIBs: in some areas, this had led to waning attendance from some key health agencies:

"Even after two years, I think they're still trying to find their feet in terms of what exactly they're trying to do". SCR

- variable levels of commitment and effectiveness: LIBs had been embraced more fully and were seen as functioning better in some areas than others:

"We've got a couple that are very active Local Integration Boards and they are being quite proactive in terms of what they do ... whereas others - I wouldn't want to say they were less effective but they haven't been adopted with the same enthusiasm". SCR

"There's been LIBs, in some of the areas, I think with patchy effect...Some are better than others". Provider

- insufficient sensitivity to local context: LIBs were widely regarded as a valuable mechanism for sourcing support and referrals and fine-tuning implementation and delivery to fit local context. However, there was a view in one locality that 'piggy-backing' the LIB on an existing programme board had obvious benefits in terms of established partnerships but perhaps made it less tailored to the needs of the WorkingWin:

"It probably didn't truly reflect what you would need in terms of a local implementation group. ... we didn't have the key providers on the group or a rep for general practice... because the [name of programme] people knew each other it almost stayed the same network [but] could have been a new network. So that's a...resistance to change". Public Health

- limited engagement of some NHS partners: A small number of interviewees questioned whether some LIBs had sufficient engagement from NHS partners: "Potentially there could have been a stronger health perspective" (Local Authority). There was a sense that public health had, at least initially, been overrepresented relative to NHS agencies with a corresponding lack of clinical perspectives.

- a reluctance to acknowledge and address issues: One minority view was the agencies attending LIBs tended to promote their organisational strengths rather than acknowledge and address problems. Providers also feared that challenging services who they received funding from could compromise future funding opportunities.

- the constraints of operating as an RCT: The role of LIBs was seen to be limited by the RCT element of the WorkingWin which narrowed their ability to shape the programme: 
"I think that because this has been more of a medical trial, it's been quite controlled and therefore the Integration Boards have had less of a role. They've had a role in referring and communicating, but they've had less of a roll in sorting the solutions than probably they might have done with the other programmes". SCR

\subsection{Final reflections}

Findings clearly indicate that WorkingWin is widely seen as distinguished by its local co-designed approach which has enabled local partners to feel like they have ownership of the programme. The benefits around consistency and efficiency of having a single, effective provider delivering services across all five contract areas was seen to outweigh the possible loss of sensitivity to local context.

Local co-design was considered to add value to WorkingWin by creating a shared sense of ownership and trust; enhancing the credibility of programme and commitment from partners; and harnessing pre-existing local infrastructure, networks and relationships to support implementation and delivery. At the same time it was recognised that differences at the outset in local infrastructure, relationships and cultures meant more work had to be done in some areas than other to secure the support and involvement of key health services.

Findings also highlight both the benefits and challenges in using LIBs as a mechanism for oversight and supporting implementation and delivery. On the one hand, they have played an important role in developing local networks and relationships, identifying and responding to implementation and delivery issues locally, and driving integration of health and employment activities. One interviewee expressed a view for example that "it would be good to keep them going" (SCR) as a legacy of WorkingWin to sustain partnership working in the city region.

On the other hand, there has been variable levels of commitment and effectiveness among LIBs, a lack of clarity over purpose in some cases, and limited engagement of certain health partners. This perhaps highlights the need for any successor programme to provide more support and guidance around the role and composition of LIBs without compromising the ability of partners to develop LIBs in a form most appropriate to their local context. 


\section{Integrating health and employment systems}

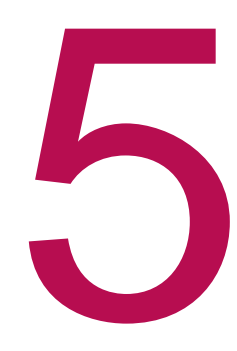

\subsection{Introduction}

Closer integration of health and employment systems is a key ambition of the WorkingWin. It reflects growing national and local interest in how employment support can be configured across policy domains and different tiers of government to improve its effectiveness and efficiency. At its heart is recognition that addressing barriers to work requires support across multiple domains that encompass not just employment and skills but also health, housing, families, finance and other policy areas. The emphasis on co-design and partnership within WorkingWin recognises the need to bring together organisations within the employment and health systems to collaborate on the design, implementation and delivery of the programme.

A recent report ${ }^{4}$ has defined local integrated employment support as:

"the bringing together of the range of partner assets at the local level to create a local ecosystem of aligned, mutually reinforcing whole person employment support in order to better support individuals, make more effective use of scarce budgets and services, and improve outcomes for people and places".

It goes on to develop a typology of integration which can be understood both in terms of the different vertical dimensions of integration and the horizontal extent of integration as outlined in Figure 1 below:

${ }^{4}$ Whitworth, A. and Murphy, R. (2018) Local Integration: Harnessing the potential for public policy, A report by the University of Sheffield in collaboration with the Mayoral Combined Authorities and Core Cities. University of Sheffield: 
Figure 1: A typology of integration

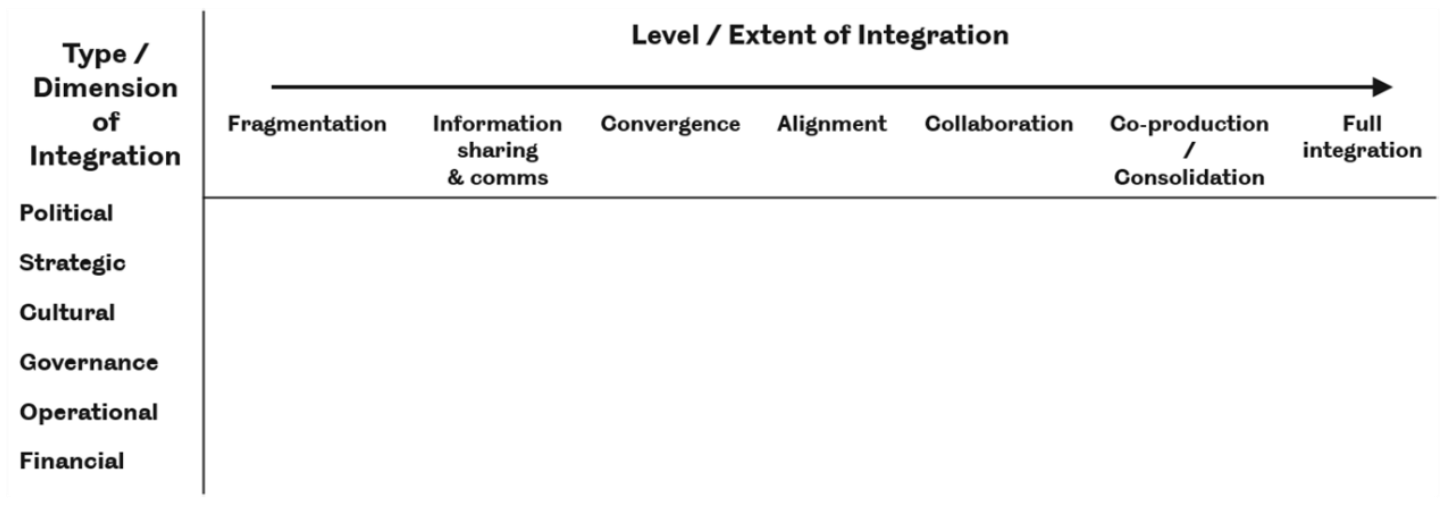

The dimensions of integration can be understood as:

- Political: Senior political buy-in to deliver and support interventions

- Strategic: A shared collective vision of objectives and targets.

- Cultural: Openness to collaboration, new ways of working and different approaches and values

- Governance: Cross-cutting governance mechanisms to co-ordinate and align existing siloes of activity.

- Operational: Collaboration between staff and organisations on the ground (e.g. around data sharing, co-location, co-case management, staffing, processes and ways of working).

- Financial: Financial alignment and flexibility to develop locally integrated strategies and services.

The extent of integration is defined as:

- Information sharing and communications: informal relationships between services and organisations including ad hoc information sharing and communication around programmes, services and clients.

- Convergence: policy actors recognise other actors and may adjust their separate objectives to begin to align, but there are no direct interactions between organisations or services.

- Alignment: organisations or teams begin to interact directly to consider their interdependencies and to mutually adjust objectives to aid their alignment.

- Collaboration: still independent organisations or teams formally share activities and work together as equal partners with common goals, activities, documents (e.g. strategic plans, action plans) and outcomes. There remains however no physical integration of staff, services or processes.

- Consolidation: physical integration of staff, services and processes are additionally seen.

- Full integration: full physical and non-physical integration of staff, services and processes (e.g. one stop shops).

This typology of the dimensions and extent of integration provides a valuable framework to explore the integration of health and employment systems within WorkingWin in this section. It begins by exploring the political and strategic dimensions of integration, particularly in terms of the involvement of key stakeholders 
in the ICS and CCGs. It moves on to consider the operational dimension of integration with a specific focus on referrals and co-location, before reflecting on the extent of cultural change in values and ways of working in partner organisations. The governance dimension has been explored elsewhere (see section 4.4 on LIBs) while the financial aspect is not covered here as it was not a central theme within this research.

Finally, the section concludes with findings on the factors that constrain and enable integration. Throughout, the focus is on the engagement and role of key health partners, particularly clinical services. Their involvement is critical to the success of a programme with ambitions to develop broader and deeper partnerships beyond organisations such as local authorities and DWP that are typically involved in delivering employment support.

\subsection{Political integration}

Interviews explored the extent to which health partners had engaged with the programme and how this varied across and within health services. There was a widespread view that WorkingWin had successfully secured buy-in at a senior strategic level within the ICS, CCGs and public health. These senior level champions played an instrumental role in engaging clinical services and practitioners, although engagement at this level remained more variable in earlier phases as previous sections have explored. Champions were critical in securing commitment, highlighting appropriate channels of communication with clinicians, and identifying key staff within organisations who could support implementation and delivery:

"It was a mixture between the strategic level endorsement and the 'I can tell you how you can weave your way into finding the right people who can unlock lots of referrals or relationships'". Public Health

"Getting senior buy-in, working with the CCG commissioners going to the primary care joint commissioning forum. There was a certain level of them helping to understand what channels they could use to spread the message and really get the right sort of information in at the right point of the system". SCR

This suggests that political integration at a senior level was achieved within WorkingWin. However, this was limited by some notable gaps on the steering group including individual CCGs as well as managers below Chief Executive level working more directly with frontline clinical teams. This has implications for the extent to which it translated into operational integration, as gaps meant that messaging and advocacy did not always reach frontline clinicians: "They were less warmed up" (Provider). Some clinicians in acute and primary care needed convincing that they should refer into the programme and make conversations about employment part of consultations with patients.

\subsection{Strategic integration}

Interviewees reflected that there was a good level of strategic integration where senior stakeholders shared a collective vision of objectives and targets. One interviewee observed, for example, that all members of the Steering Group were signed up to the vision of work as health outcome. On the typology above it could be regarded as signifying alignment in terms of the extent of integration, as organisations began to mutually adjust objectives to create a shared vision of what joint work-health provision should look like. 
Strategic integration was driven where organisations were already persuaded of the importance of the joint work-health agenda and therefore more likely to recognised Working Win's potential contribution towards realising objectives in this space. In some cases this reflected alignment with national strategies such as goals in the NHS England Long Term Plan around moving beyond a narrow focus on illness to consider wider social needs.

More concretely, strategic integration also occurred where organisations at a local level had direct experience of delivering employment support or IPS within their core service. WorkingWin felt like a "natural development" (NHS Trust) for Mental Health Trusts and IAPT teams and, in some cases, MSK teams who already provided employment advice and support as part of recovery:

"They totally got the connections between the sorts of barriers people were facing and the solutions needed to unblock those issues". Public Health

"We certainly saw good responses from the IAPT service and musculoskeletal service... and I think that is because they, by their very nature, see work as a sort of outcome for people". Public Health

It was more of a departure for other areas of the health system, particularly among primary care practitioners which may explain the lower level of engagement from some GPs.

Designing WorkingWin around a proven IPS model which has already been rolled out in NHS mental health services also helped to secure commitment as senior strategic stakeholders were reassured of its efficacy: "If it had been something completely leftfield you might not have got the buy-in" (Local Authority). Other interventions including the introduction of social prescribing were further seen to demonstrate the viability and potential value of services addressing the social determinants of health. In addition, the deployment of Employment Advisers in IAPT services nationally has provided additional familiarity with, and support for, integrated ways of working.

\subsection{Operational integration}

Operational integration refers to collaboration between staff and organisations on the ground. Interviews focussed in detail on two aspects of this - referrals and co-location - which are explored in detail below. Some smaller scale reflections on collaboration around communications are also presented.

\subsubsection{Referrals}

This section first considers referral volumes before presenting more detailed reflections on each of the three clinical groups providing referrals (GPS, MSK and IAPT). The findings show that operational integration in terms of referrals was largely successful, albeit to varying degrees by clinical group, areas and individual clinicians.

\section{Referral volumes}

Referral data collated by the provider shows that referrals from the three health service pathways (GPS, IAPT and MSK) accounted for half (51 per cent) of all referrals (Table 3 below). In terms of volumes by source, IAPT provided most referrals (22 per cent) followed by GPs (19 per cent) and MSK ( 9 per cent). A large proportion of self-referrals (which account for 22 per cent of all referrals) will also have come via GPs where participants were given a leaflet or received a text from their practice and went onto the WorkingWin website to self-refer. 
Table 3: Referral volumes and proportions by pathway

\begin{tabular}{lrr}
\hline Organisation & $\begin{array}{l}\text { Total } \\
\text { Referrals }\end{array}$ & $\begin{array}{l}\text { As \% of } \\
\text { all } \\
\text { referrals }\end{array}$ \\
\hline IAPT & 1880 & 22.1 \\
\hline Insight Healthcare & 248 & 2.9 \\
\hline RDaSH & 680 & 8.0 \\
\hline Sheffield Health \& Social Care & 580 & 6.8 \\
\hline South West Yorkshire Foundation Trust & 372 & 4.4 \\
\hline GP & 1619 & 19.1 \\
\hline MSK & 788 & 9.3 \\
\hline Barnsley Hospital Foundation Trust & 24 & 0.2 \\
\hline Doncaster \& Bassetlaw Teaching Hospitals & 408 & 4.8 \\
\hline Rotherham Foundation Trust & 30 & 0.4 \\
\hline Sheffield Teaching Hospitals & 326 & 3.8 \\
\hline Private & 177 & 2.1 \\
\hline Public & 1060 & 12.5 \\
\hline Self & 1886 & 22.2 \\
\hline Voluntary & 1079 & 12.7 \\
\hline Total & 8489 & 100 \\
\hline
\end{tabular}

The table also shows the variability across areas and sectors. This in particularly evident with referrals by MSK teams which are significant in two Trusts (5 percent in Doncaster \& Bassetlaw and 4 per cent in Sheffield) but negligible in Barnsley and Rotherham. By contrast, referrals from IAPT by area are more consistent although there is still a considerable difference between the highest (RDash, 8 per cent) and lowest (Insight, 3 per cent) referrers.

IAPT

Engagement with, and referrals from, IAPT teams at a local level was widely seen to work well. In Barnsley it was described as a "really smooth process", made easier by the fact that the IAPT team were already working with clients with mild to moderate mental health conditions and having discussions around employment "all the time" (Local Authority). Sheffield and Rotherham were also highlighted as areas that had good levels of referrals from IAPT. However, one Doncaster-based respondent noted that referrals from both IAPT and MSK teams varied significantly by clinicians as only a small minority from each service really "embraced" WorkingWin and made high levels of referrals while others were "sending absolutely nobody" (Local Authority).

MSK

Engagement of MSK services in terms of referrals into WorkingWin was described as highly variable. "Pockets" (SCR) of good practice in two Trusts (Sheffield Teaching Hospitals and Doncaster \& Bassetlaw Teaching Hospitals) were contrasted with lower levels of engagement elsewhere, as also reflected in Table 3 above.

In Bassetlaw, MSK referral volumes into WorkingWin were extremely low and this was attributed to the lack of involvement of senior MSK service staff in the Steering Group as well as the stronger initial focus of the programme on mental health issues. Local 
engagement sessions were held in Bassetlaw to explain the programme to the MSK team, but one interviewee suggested earlier involvement at the co-design phase would been beneficial. There were also challenges in establishing MSK referral routes in Barnsley due to the service provider being hard to engage following a recent recommissioning process. Moreover, a lack of space prevented WorkingWin Employment Specialists from co-locating with the Barnsley MSK team.

\section{GPS}

GPs were regarded by some stakeholders as a group that often had little prior experience of supporting patients around employment issues beyond certifying medical leave: "If GPs are writing sick notes, are they thinking about the bigger picture? That's debatable" (NHS Trust). Correspondingly, interviewees observed considerable challenges in securing commitment from GPs despite extensive engagement work, although this varied across localities.

"But the [WorkingWin team] have struggled to be part of the team in GP practices ....we sort of gave up on GPs after a while, because it was a lot of work for very little reward". SCR

"GPs were very slow and very variable...I mean, I think Sheffield GPs were well engaged...CCGs did a good job [but] some GPs hardly got engaged". NHS Trust

“We have pockets of some GPs that just don't engage and we've tried everything”. SCR

There were some exceptions, however, most notably two GP Practice clusters already involved in clinical research:

"It's a research trial and you can get natural buy in from that cluster because they are about research...... These GPs believed in research and they understood it". SCR

One stakeholder in Bassetlaw also noted how GPs in their locality had been responsive to the central premise of WorkingWin that employment is a key determinant of health. Another interviewee described how those GPs who proved the exception by engaging and referring higher volumes tended to be those at "the front of that curve in terms of a more holistic approach to general practice" (Public Health). Good engagement was also attributed to recognition of the potential benefits to workloads of reduced attendances where patients could be supported to return to work.

It is also important to note that the data shows GPs made nearly a fifth (19 per cent of all referrals) into the WorkingWin, so perceptions of primary care as being the least engaged of clinical services perhaps reflects highly variable practice across GPs rather than a failure of the sector as a whole.

\subsubsection{Co-location}

Co-location was seen as an important element of service integration and was crucial in terms of fidelity to the IPS model. There were mixed views on the extent of integration achieved around co-location of Employment Specialists in clinical teams.

On some sites there was no co-location at all such as where GPs or practice managers simply provided a leaflet to patients to encourage them to self-refer. In Rotherham, efforts to co-locate employment specialists with the hospital MSK team were unsuccessful due to a combination of staff changes, the complexity of training new staff around the Trial, and the short timescales for implementation. 
Other factors which hindered effective co-location included a lack of space, especially on MSK sites, not being able to operate in the same room as clinicians, and host organisations undergoing restructuring or staff turnover. There was a feeling among one interviewee that health partners had not fully supported opportunities for colocation, particularly where they charged for room space: 'We would have hoped that health partners would have seen the benefits of the service, embraced it and given them [free] space". (Local Authority)

In some sites and services, however, co-location was seen to be at least partially achieved. One stakeholder made the distinction between physical co-location and joint case working, with the latter less likely to be practised:

"In Bassetlaw, they really feel like the Working Win team is part of the [IAPT] team. So they are already mourning their loss. They are co-located with IAPT, they are in the libraries. So they say co-located, but...I actually don't think they are colocated, I think they have got a desk and I think that is totally different. They are not part of the case conferences". SCR

Nevertheless, the interviewee felt that Working Win had catalysed progress towards full co-location and provided a valuable foundation which could be built upon:

"I don't think we have achieved pure co-location, but my challenge is going to be to the ICS, look where we've got, look where we can be". SCR

Co-location was felt to deliver a number of benefits including encouraging and discussing ref errals, building partnerships, creating a feedback loop between frontline services and the Steering Group, and providing opportunities for clinical practitioners to get immediate responses to queries:

"If you sit in a GP surgery every Thursday afternoon and they are referring to you and they are getting results, they'll remember that...once you are embedded they'll keep referring, ... you are making it easy for them. 'Oh I'll refer them to [the Employment Specialist] on a Thursday because I know he's in'". SCR

"What was really useful was staff were around and so if IAPT staff wanted to run things past them or ask questions, discuss if somebody was appropriate then they were able to do that directly with the [WorkingWin] workers." (IAPT)

Overall, it could be suggested that co-location where practised fell somewhere between consolidation, where there is partial physical integration of staff and services and processes, and full integration of staff and services within the typology outlined above. This is arguably a significant achievement given that these are the two highest levels of integration possible. It is also important to note that co-location not only supported service delivery in terms of referrals and joint working around cases but was also a valuable mechanism for building relationships between organisations. By bridging the work-health divide in this way it undoubtedly contributed to cultural integration as discussed further below.

\subsubsection{Communications}

Aside from referrals and co-location, WorkingWin also encouraged operational integration in terms of closer joint working between the communications teams in the ICS and SCR to refine messaging. A prior history of joint working on health-focussed programmes made it easier to collaborate around an employment agenda that was, from an ICS perspective, relatively new. The ICS communications team played a key role in working through senior intermediaries including chief executives, medical directors and chief nurses to work out how best to engage frontline staff: "Here is the 
programme, how can you support staff to tell people about it?" (ICS). This could be regarded as a form of collaboration on the horizontal scale above.

\subsection{Cultural integration}

Cultural integration encompasses openness to collaboration, new ways of working and different approaches and values. Interviewees reflected on a number of ways in which this had been achieved within WorkingWin, as well as the limits to cultural change. Stakeholders working at a strategic level within health organisations suggested that WorkingWin had deepened their engagement with the joint work and health agenda. This was not always a wholly new way of working as initiatives such as social prescribing had already demonstrated a recognition of the need to address the social determinants of health (see 5.3 for further discussion of senior level strategic integration).

Equally significantly, there was now a view that the WorkingWin programme had begun to change the values of clinicians towards recognising the importance of employment in shaping health outcomes:

"In a clinical setting it is starting to happen now, where you are beginning to bring employment into the conversation, identifying referrals, so it wasn't a natural thought process for a GP, or a recovery worker thinking 'work will make this person happier' because they were thinking about the mental health recovery or the physical recovery rather than bringing employment into the conversation". SCR

"Breaking down some of those barriers between employment and health practitioners and GP groups and all of that has been very positive". SCR

"Getting physical health services to be more switched on to employment support, that was new...The scale of GP relationships was new". Provider

However, this is perhaps also a risk noted by one stakeholder of 'preaching to the converted':

"In Doncaster...because it was a pilot... those who were already interested in work and health as GPs or mental health practitioners, they were the ones who got involved... and those who weren't interested in work and health because they saw it as a pilot thought, 'oh, we won't engage at the moment'". Public Health

Moreover, this shift in culture had not happened among all clinical services and practitioners. One stakeholders suggested that GPs - with some notable exceptions did not see employment as one of their responsibilities: "We've still got a long way to go"(Public Health). At the same time, they observed that the support of the CCG and ICS at a higher strategic level and the positive feedback on outcomes from the programme is starting to shift those attitudes.

Cultural integration was also evident from the new or strengthened forms of partnership that had developed through the programme. There was a perception that WorkingWin had "deepened links" (Provider) with services that had already been engaged with the employment agendasuch as IAPT. One CCG stakeholder also noted that while they already had a relationship with the SCR it was the first time they had worked on a programme together. New connections had been forged between health and employment systems: "It's so much more joined up than it was before the programme" (Public Health) 
There were also important connections made across the public and clinical health divide. One stakeholder working in Public Health noted how it had enabled them to build a stronger relationship with clinical health services such as talking to the Primary Care Commissioning Board about work and health: "Would that have been on their agenda without the Trial? It gave us a way in, a hook" (Public Health). Another local authority respondent noted that "I've never really had to engage with health partners. We've made some inroads now" (Local Authority).

Overall, there was a sense that cultural integration had been facilitated through WorkingWin which both strengthened existing ways of working and values round the work-health agenda while also bringing new relationships and practices to fruition. These are clearly important forms of collaboration as described in the typology above. At the same time, the limited ability of any programme to shift institutional cultures significantly in a relatively short period of time needs to be recognised. As one stakeholder observed, there is "no button you can press to get a quick change in behaviour" (NHS Trust) in some parts of the health system, especially primary care.

\subsection{Factors enabling integration}

Discussions with stakeholders explored the factors that explain the nature and degree of integration between employment and health systems. A number of enabling factors were identified that can be categorised in relation to their contribution to political and operational integration.

In terms of political integration, the endorsement of key champions within health organisations including the ICS Chief Executive and CCG commissioners played an instrumental role in engaging clinical services and practitioners. Factors which contributed to securing this endorsement included:

- $\quad$ SCR and Provider time and effort: This was seen as critical in identifying and securing buy-in from some of these champions.

- A CCG-led procurement process: One stakeholder felt that procurement through the CCG rather than the SCR helped to pull in key health partners including commissioners from all five CCG areas. Senior stakeholders were persuaded by the advantages of using the dedicated CCG procurement vehicle as tendering WorkingWin as an NHS contract made it easier to secure ethical approval and the permissions needed to operate and collect data on NHS sites.

- The positioning of WorkingWin as a health-led employment programme: Key to securing political support was the framing and design of WorkingWin. Its efforts to genuinely embed itself within health systems rather than health featuring as 'add-on' in a standard employment programme helped to garner support.

"It traditionally would have been in the employment camp, but because this was taking a medical approach to it, it looked and felt different to people and I think that's been to its ultimate benefit". SCR

Alongside this, operational integration was supported by a number of factors. This included having the right expertise and processes in place to implement a complex, NHS-based RCT and to encourage key clinical services to make referrals:

- The co-design process and senior strategic support: Initial work around codesign secured awareness and buy-in to WorkingWin from health service leads and senior managers. This in turn proved critical in 'opening doors' for the provider to quickly put co-location arrangements in place with clinical services once appointed. 
- $\quad$ NHS research expertise: NHS partners played a critical role in providing staff with expertise in undertaking research on NHS sites and gaining ethical approval from the Health Research Authority. This secured the involvement of clinical services and ensured the trial could proceed much quicker than may otherwise have been the case. For example, this expertise helped to obtain the letters of access required for Employment Specialists to work in NHS settings. The NHS research lead also helped secure Clinical Research Network funding to pay GPs for referrals which boosted engagement.

- Persistence and flexibility of the Provider: While the SCR played a key role in securing senior-level strategic commitment in the early phase, the Provider proved critical in gaining and maintaining the buy-in of frontline clinicians as the programme evolved:

"There was an incredible amount of perseverance from the Provider to keep going, when GPs were saying, 'no we're not doing it'... [They] did a lot of work chasing up GP surgeries, to keep them involved". SCR

"Where referrals... worked well from GPs was ... where the WorkingWin manager was able to spend more time with brokering relationships and getting to know them". Public Health

Specific measures were also introduced to support this work including the introduction of incentives for referring 15 patients or more and the provision of feedback on the experiences of WorkingWin participants to boost GP referrals. Referrals snowballed where practitioners became convinced of the benefits to patients:

"So once they've seen somebody go through their trials... and seeing that it's benefiting people or that there is an offer there, then people will refer". Public Health

- Peer advocacy and learning: Practitioners with positive experiences of the programme played a key role in persuading colleagues, as one member of the WorkingWin team involved in a GP workshop explained:

"A couple of GPs who happened to be in the room said 'Oh it's been fantastic, I referred $X$ and $Y$ patients and it worked really well'. And suddenly you see other GPs sit up... You get one zealot who encourages other professionals to listen to them and give some evidence-based practice they've not thought of". SCR

Shared learning between practitioners also supported higher levels of engagement. For instance, one GP cluster in Sheffield helped another cluster in Barnsley around using a mobile-based app to communicate information about the programme to patients.

- Streamlining technical processes: Investment in technical processes was seen to encourage the engagement of health partners by creating a simple and quick referral process:

"I think what we definitely got right, was keeping the referral system very simple...only asking for information that we absolutely needed rather than lots and lots of laborious paper forms". Provider

At the same time, GPs still had to switch between IT systems to make referrals which meant it did not function as the 'magic button' originally envisaged. 


\subsection{The limits of integration}

A number of examples of successful integration have been outlined in this section which show how health services and practitioners have played a key role in supporting WorkingWin. At the same time, stakeholders observed the limits to integrating employment and health services, particularly as the latter is a complex system facing acute demand at this time. Issues and challenges identified as constraining the ability of the Working Win to engage health partners included:

- Delays in establishing the Trial in acute settings: The challenges presented in establishing the RCT in clinical settings in the early phase may have limited referrals. For example, some MSK teams were described as "keen" but constrained by delayed implementation:

"I know for Sheffield Teaching Hospital it took ages because, again, because of the [delays in getting ethical agreements and permissions to access sites agreed] they were slow to get started and...physios were really keen but...they couldn't get going". NHS Trust

Delays in implementing the RCT were attributed to both local and national factors. Once again, this highlights the need for sufficient time and resource for co-design and mobilisation to ensure all processes and systems are in place to enable clinicians to make referrals at the point of programme launch.

- The time-limited nature of the programme: Stakeholders described cynicism or caution among health practitioners regarding the sustainability of health and employment programmes which may have limited engagement:

“We've seen a number of things like condition management programmes... come and go. And even where things have been shown to work...for one reason or another they've not continued...mostly down to sort of national resourcing". Public Health

"You think, how much work are you going to have to put in and then it is going to disappear? If something is only funded for a year then it has to be minimum effort to engage with it". IAPT

- $\quad$ Challenges in engaging GPs: The lower levels of engagement from some GPS both in terms of operational (e.g. referrals) and cultural integration was ascribed to a number of factors including:

- $\quad$ acute demand and time pressures

- lower levels of engagement with the work-health agenda compared to other health services

- $\quad$ the need to get all GP practice staff on board

- the inclination of some GPs to shield patients from work to manage health conditions

- concerns about damaging trust and if patients referred into control group

- multiple programmes they can refer into

- the time taken to put all processes in place e.g. recruitment by text message.

- Concerns about the RCT element: Running the programme as an RCT was seen by some stakeholders to deter referrals from some clinicians concerned about the impacts on patients allocated to the control group: 
"There were concerns around the trial, about it being an RCT and I think the phrase used was 'using people as cannon fodder'...concerns from elected members, the voluntary sector, health partners". SCR

"Referrals would definitely have been higher if it hadn't been a [RCT] research project". Public Health

- Issues with data protection and information governance: Some GP surgeries initially used text messages to send information about the programme to patients. This was halted, however, when it became clear that the necessary ethical permissions were not in place.

- Competition from other programmes: Health partners were seen as less likely to engage and refer where there were alternative programmes that had lower barriers to entry or from which they had received more recent communications:

"There was so much going on in general practice... the fact that [a] practice hasn't engaged with the WorkingWin approach doesn't mean that they weren't engaging with the other nine change initiatives that were happening". Public Health

"It was hard to get traction...Probably because someone else [from another programme] had presented the week after...I was disappointed with the lack of consistency from the health side". Local Authority.

This issue was further exacerbated by delays in implementing the RCT element of WorkingWin. It led to waning support from practitioners able to refer into other programmes in the meantime.

\subsection{Final reflections}

Overall, there was sense that integration had been successful in a number of ways, particularly in terms of political integration in securing the buy-in of senior stakeholders within key organisations such as the ICS and CCGs. These organisations were brought together with the SCR and local authority partners to work in partnership in new ways. Strategic integration also occurred where WorkingWin aligned with national strategies and initiatives promoting the joint work-health agenda within which partners were involved. Prior experience of delivering integrated health and employment indicatives also underpinned strategic commitment.

These forms of integration proved crucial, in turn, in engaging frontline services and supporting operational integration, especially around referrals and co-location. It also proved effective in some instances in promoting cultural integration where services and clinicians experienced or implemented changes in values, practices and partnerships. These achievements should not underestimated given the challenges health-focussed employment support programmes often face in engaging health partners, particularly from within NHS clinical services.

Perhaps inevitably, there are limits to the nature and extent of integration, most notably where gaps in representation at the Steering Group led to lower levels of engagement from some clinical teams in localities. This underscores the importance of securing as full a level of political and strategic integration as possible by engaging the right organisations and stakeholders at the outset to facilitate implementation and delivery. However, this is not simply a story of a single clinical sector failing to engage, even though GPs were often singled out as challenging to work with. Rather, integration varied significantly both across and within clinical groups and localities with some practitioners championing the service while other colleagues proved more reluctant to get involved. 
Key learning from the programme, therefore, is to understand the different dimensions of integration and the relationships between them from the outset in order to minimise missed connections and opportunities. For example, any successor programme would benefit from having all clinical groups represented as early as possible, as well as ensuring expertise in programme evaluation and delivery on NHS sites is in place. This is also a need to focus more closely at an earlier point on what integration should look like and how it might be achieved at a local level. As one local stakeholder reflected: "In some ways integration worked at the city regional level but then locally, particularly in Doncaster, I knew we struggled, with GPs" (Local Authority).

It may never be possible to engage all services and health professionals equally. However, more time and resource allocated at the co-design and mobilisation phase may help to identify and address some of the gaps in representation as well as potential implementation issues. This could then encourage closer operational integration further down the line. 


\section{Lessons, legacy and opportunities}

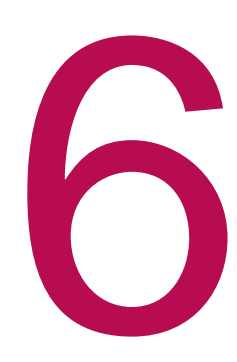

\subsection{Introduction}

It is increasingly recognised both that health can be a barrier to employment and that employment is a social determinant of health. WorkingWin is part of this growing focus on addressing the health-related barriers to work but is also, in many ways, distinct from previous rounds of central government-led employment support strategies, policies and interventions. Distinguishing features include:

- leadership, management and governance of the programme by a combined authority, local authorities and LIBs

- $\quad$ an emphasis on co-design and working with local partners

- a voluntary approach

- the use of a modified IPS model

- a strong focus on integration of health and employment systems

- the delivery and evaluation of the programme through an RCT

- $\quad$ and provision of support to those in work but on medical leave.

These distinctive elements mean there is much that can be learnt from WorkingWin from the perceptions and experiences of stakeholders involved in the programme. This final section draws on their accounts to reflect on key lessons in relation to co-design; engaging health partners; the use of an RCT; and the delivery model. It moves on to consider the legacy that WorkingWin has left behind in terms of enduring changes in organisational cultures, partnerships and engagement with in the work-health sphere. It concludes by reflecting on the opportunities to develop future forms of healthfocussed employment support in the city region in collaboration with national, city regional and local health partners.

\subsection{Lessons}

\subsubsection{Co-Design}

Co-design has been an integral feature of WorkingWin and Sections 3 and 4 highlighted the valuable role that it played in enabling a range of local partners to contribute to the design, implementation and real-time improvement of the programme. It also enabled key 'connectors' on the Steering Group, sub-groups and LIBs to engage with, and secure the buy in of, local health services and clinicians. Many interviewees contrasted this positively with top-down, central government-led interventions where opportunties for co-design are limited or negligible. 
At the same time, co-design inevitably creates challenges. Wider lessons that emerge from the experiences of embedding co-design within WorkingWin include:

- Local areas need to take responsibility for driving cross-silo forms of delivery and governance if they want to successfully implement work and health interventions. WorkingWin has shown that this requires a commitment to codesigned ways of working where traditional divides between employment/skills and health are bridged by engaging a full range of partners from across different sectors. The innovation shown by WorkingWin in bringing the ICS and NHS partners directly into the process of designing, commissioning, implementing and running the programme with SCR was seen as integral to its success. It dissolved some of the traditional boundaries between local employment and skills provision and separate NHS commissioned and led IPS interventions.

- The importance of identifying and engaging the full range of health partners needed at an early stage for co-design to be as effective and inclusive as possible. Stakeholders clearly felt that WorkingWin secured an impressive degree of commitment from key health partners such as the ICS, Trusts and CCGs including senior staff. However, hindsight suggests that greater involvement of local clinical services and professionals at an early stage in co-design may have helped secure stronger commitment and referrals from the three main referral services (GPs, IAPT and MSK) and smoothed the implementation of the service on NHS sites.

- A related point of learning is the importance of allowing sufficient time and resource at the mobilisation phase to undertake and perhaps expand the scope of engagement activities. This includes sufficient time for conversations with partners before the programme goes lives. There may be methods for securing greater engagement from clinical services such as ad hoc 'dial-ins' to the Steering Group at the co-design phase. At the same time, there must be a degree of realism as it would not be practical or desirable, for example, to involve all services from all areas in every Steering Group meeting. Crucial, therefore, is also understanding how best to maximise 'two-way' communication between Steering Group leads and local partners to ensure opportunities for all services to contribute without overloading the co-design process.

- Governance through LIBs worked well in many ways but there were some issues with clarity over role and lack of representation from some health partners. This perhaps highlights the need for any successor programme to provide more support and guidance around the role and composition of LIBs without compromising the ability of partners to develop LIBs in a form most appropriate to their local context

- Earlier engagement with VCS organisations as formal partners in the codesign process could have enabled WorkingWin to benefit more from referrals and provision from within the sector. VCS organisations played an essential role in terms of referrals on the one hand, and specialist support on the other, but this tended to be patchy and ad hoc. It worked best where there was genuine colocation:

"The programme workers tapped into all the wider third sector provision such as debt advice, clothes for interviews and lots of things around building confidence". Public Health

- WorkingWin highlights a need to bring in relevant NHS research expertise (e.g. NHS research staff) at the earliest possible stage to resolve issues up front and keep implementation on track, rather than having to address them a later point: 
"It was a research project led by non-NHS people within the NHS which meant it is important to bring in people who understood that context at an earlier phase". CCG

\subsubsection{Engaging health partners}

Engagement of health partners at both a strategic and operational level and efforts to strengthen cultures of practice to embrace work as health outcome were key ambitions of WorkingWin. Findings in Section 5 shows that the programme was successful in many ways in achieving political and strategic integration through the involvement of key health partners as well as driving cultural integration through promoting new ways of working. Operational integration in terms of securing the commitment of some clinical services and professions and genuine forms of co-location proved harder to achieve.

Stakeholders interviewed reflected that some parts of the health service played a fuller role in WorkingWin than others:" We've been more successful in engaging critical health services in some parts of the city (region) than others"(Provider). Key points of learning are provided where engagement was more successful. This was attributed to a range of factors including:

- Taking a "motivational and enabling approach"that encourages clinicians to see the value of, and embed, 'work as a health conversation' in their practice. This was regarded as an ongoing process:

"Continuing with working with health professionals to have a more positive view of work and a slightly less protectionist approach. And [emphasising that] if you want to do it you can do it". Public Health

One locality had secured Public Health England funding to deliver some training events on 'Work as a Health Conversation' which was aimed at GPs and NHS service providers to persuade them of the benefits of getting involved with WorkingWin. This highlights for continuous training and education work to promote working cultures receptive to integrated health and employment initiatives.

- Identifying champions 'on the ground' within organisations who are able to promote WorkingWin in partner organisations, rather than on relying on more senior staff to cascade expectations down. Clinician leaders can play a particularly vital role in keeping health service teams engaged:

"So, it needs that clinical leadership and championing of it on the ground to make teams engage in it". MSK

- Recognising the importance of good communication and "using a language that everyone understands" (Public Health) as health and employment partners do not always use the same terminology. The SCR team managing WorkingWin was also seen to play a key role in engaging health partners through a genuinely consultative approach:

"The tone and style was done very well. It was very inclusive and they were actively listening". NHS Trust

- Significant investment in time, resource and capacity upfront to build the trust and commitment on which successful working with health partners relies:

"So, when we've done this sort of thing in the past with primary care, we've always underestimated the amount of time you would need to go out and spend with 
practices, building relationships....it's almostlike they've got to trust you as people before they'll refer people into your sort of service...If we were to do it again, you know, I would be thinking about... how do we build relationships with the practices and have we got enough capacity to do that?" Public Health

\subsubsection{RCT as an evaluation tool}

Delivering WorkingWin as an RCT posed political challenges in terms of getting it accepted by elected representatives as well as some organisational leaders. Operationally, it also proved difficult to implement and required NHS research expertise to support the process. There are also suggestions that it may have deterred referrals from some clinicians reluctant to see patients placed in the control group. Despite all this, many stakeholders, especially those in health services with experience of RCTs, recognised its legitimacy as a research method given its potential to generate highly robust evidence.

It is by no means certain or that any future iteration of integrated health and employment support within the SCR would be delivered through an RCT so identifying lessons may, to some extent, be academic. Nonetheless, it is worth reflecting on the experience given the extent to which it shaped WorkingWin and also the prominence it assumed in stakeholder reflections.

In particular, the experience of WorkingWin raises questions about the appropriateness of an RCT for an employment support intervention given that the design was not completely experimental or untested, and other less contentious evaluation methodologies were available:

"It's not a new drug that you're not quite sure about. You know that people who will be offered the service will get a better deal out of life than before". NHS Trust

"There was a sense that some people were wedded to an RCT, and that was the only methodology that was appropriate... when I think ... there may have been alternatives... It felt more central[than] local, if I'm honest. You know, I've definitely had the feeling that the Work and Health Unit's view was it's got to be an RCT and that's it, and that's what we do". Public Health

This was overlaid with concerns about the delay before the RCT results become available to identify the impact of WorkingWin. This gap in the evidence base makes it harder in the meantime to seek new funding either to sustain WorkingWin or develop new forms of integrated employment and health provision in the city region. Clearly, this study is intended to provide an interim assessment of co-design activities but there may have been scope for other complementary process evaluations. There is a real risk that local infrastructure and relationships built up around WorkingWin start to fade aware before the RCT results become available.

\subsubsection{The delivery model}

There are number of key features of the WorkingWin delivery model that include voluntary participation, a strengths-based ethos, a work-first approach, employer engagement, personal action planning, and small caseloads. Many of these are part of the modified IPS model which provides the foundation of WorkingWin.

This research was not commissioned explicitly to explore the effectiveness of the delivery model in the sense of identifying what 'works and why' as this is part of the wider impact evaluation. Notable exceptions are where aspects of the delivery model such as co-location enable us to reflect on the core themes of this study around codesign, local delivery and health employment and system integration. Nonetheless, 
many interviewees provided interesting insights into the effectiveness of aspects of delivery that we have captured here to ensure key points of learning are not lost:

- The simple referral process was considered a core strength of the programme which highlights the need for streamlining the often complex and confusing landscape of, and pathways into, employment support provision:

"What was so brilliant about Working Win is that they had one phone number and everybody just [knew where to send people]...it was just the simplicity of referral that made it work. Because there was a latent acknowledgment out there that people needed to refer differently but they just didn't know how to do it". Public Health.

As the SCR continues to develop its employment and support provision this may indicate a need not just to streamline referral processes within any one programme but to develop a single gateway to triage into all provision according to need.

- WorkingWin was better suited to those with mild to moderate conditions as intended. One interview suggested this highlighted the need for other complementary forms of support to be developed for those with more complex needs such as drug and alcohol dependency. These groups are lesswork ready and may benefit from other forms of meaningful activity:

"For some people work is a big step so whether it would be widened into 'occupation' [being occupied] rather than just paid work as a mid-step...into voluntary work, training and education as I think they are all valuable steps that often people have to take to get into work". IAPT

- Co-location worked well for some health practitioners, particularly in facilitating easier referrals. It achieved the best results where co-location was genuine, for example in a community hub or local library. However, as discussed earlier (see Section 5.4.2) it often fell short of full integration in the sense of joint case working. Case conferencing could therefore be incorporated more fully in any future employment and health provision, drawing perhaps on the considerable experience, expertise and research around case-conferencing, co-location and multi-agency working seen in other services (e.g. around complex needs, probation and domestic violence).

- Positive feedback was essential in encouraging continued referrals from the same source and 'spreading the word' among peers. This highlights the value of ensuring referral agencies receive timely feedback and that opportunties to encourage peer advocacy are provided:

"The feedback loop is really important for GPs. So are we making sure that when they've referred someone and that person has had a good experience that that GP is hearing that feedback. So that they can then go 'Oh that worked did it! Oh I was just trying it and actually I will refer a few more people if I hear that thing I recommended was really useful". Public Health

"I remember putting up some of the stats up [about the programme in a meeting of GPs]... there were a couple of stats where it was very evident this was having some outcomes. And a couple of GPs who happened to be in the room said 'Oh it's been fantastic, I referred $X$ and $Y$ patients and it worked really well'. And suddenly you see other GPs sit up, and there is a little bit of competition there isn't there. And they wrote it down and followed it up with me saying 'Can you just send out some information on WorkingWin'... to me that was that peer advocacy approach to this thing that you've got to keep hold of"(Stakeholder workshop) 
- For the 'in work' cohort the flexibility of fered with regard to the timing and location of appointments with support workers was of paramount importance:

"In-work support needs that flexibility to see you when they can...ability to meet them in a coffee shop when it suited them.... an agile set-up.... offering appointments till 9 or 10". Stakeholder Workshop

- The 'strengths-based' approach in which positive attributes and abilities are emphasised appealed to WorkingWin participants and referral agencies alike. This aligns well with the 'asset-based' ethos that currently underpins most mental health support, and the 'capabilities' approach in the employment sphere.

- The balance between funding allocations for communications and delivery is important to get right. Social media was recognised as expensive but effective in generating a large number of self-referrals. However, some respondents felt that communications consumed a disproportionate amount of resource, some of which could have been better allocated to employment support activities:

"With hindsight it may be the case that more resource could have been put into the implementation and delivery of the programme rather than comms". NHS Trust

\subsection{Legacy}

Interviews explored the legacy of WorkingWin in terms of the durable impacts it has had upon ways of working in the SCR. These highlighted the extent to which the programmes has demonstrated the value of co-design in terms of creating stronger and durable partnerships. It has also supporting closer integration across health and employment systems through alignment of strategies, a valuable 'demonstration effect', enduring cultural changes in the way health services engage with the employment agenda, and beneficial spillover effects into other policy areas.

\subsubsection{Stronger partnerships}

Interviewees reflected that WorkingWin had created a legacy of durable partnerships across the health and employment policy arenas within both localities and the city region. LIBs are a key mechanism for maintaining these partnerships. These networks were considered an important achievement even if they felt short of full integration across the two systems: "We're not there yet but it's moved forward." (Local Authority)

New or strengthened partnerships were seen to provide a strong base for further expansion and consolidation of joint working around employment and health, although many noted the danger of losing momentum and dissipation of the network:

"Once the trial finishes, there is a bit of a risk that we lose any of the partnerships that we've got currently in place, or all of it sits with the provider [in terms of organisational knowledge], and it's more difficult to share it across the region". SCR.

"Because we have worked all this time to get them to start having those conversations, I don't want them to stop just because WorkingWin is finished". MSK 


\subsubsection{Closer integration}

It was noted that the health sector has increasingly embraced the notion of work as a social determinant of health. Health partners have sought to embed this within their own strategic activities while also supporting the work of partners in the employment and skills system. This cross-pollination is evident in the work of the ICS for example. It has just published its five-year plan which includes a commitment to undertake more collaborative work on programmes addressing the social determinants of health. It has also aligned its aims and activities with work being undertaken by economic development and employment and skills teams at both the city regional and local level. This represents a significant repositioning of both the ICS's core remit:

"[The change in the ICS] is not all down to Working Win but [the programme] is symbolic of a shifting awareness on both sides of the combined responsibilities of [economic] regeneration and health being one and the same thing". NHS Trust

Stakeholders mostly reflected on the integration in the sense of health partners being brought into the ambit of employment and skills policy and strategy through WorkingWin. This is understandable given the historic tendency of employment support to be delivered through, or with the support of, local authority employment and skills teams outside of NHS structures.

However, there is also movement in the opposite direction. Economic development teams in particular that have traditionally not seen health as a core part of their remit have begun to reframe strategies around the central role of health in shaping labour market participation and strength. In Barnsley for example, integration of work and health support is a strategic ambition in its inclusive economy strategy currently being drafted. The Council has also just bid for Health Foundation Shaping Places for Healthier Lives funding to support the development of joint work and health provision: "So thinking [from the Trial] is feeding through into longer-term ways of working" (Public Health).

As some respondents note, some of these developments may have happened without WorkingWin, but the programme still adds value through its demonstration effect of how ambitions around an integrated work and health agenda can be realised in practice: "Working Win has provided an example of how the system can work together" (NHS Trust). As another respondent noted, it obviated the risk that key mechanisms for promoting the work-health agenda like the ICS and LIBs become:

"talking shops.. (or just) a statement of intent.... this was showing we can all bring something to the table and mutually benefit from it. It's walking the walk". CCG

WorkingWin has significant value, therefore, in showing that this agenda can be actualised as an effective programme of employment support. It leaves a legacy of increased awareness among some clinicians in the primary and acute sectors of the links between health and employment:

"You wouldn't have had that before Working Win...[Primary care and acute care] now have a clearer understanding of the wider determinants of health, especially in relation to employment. It's raised the profile" NHS Trust

Engaging with this agenda as a legacy of WorkingWin may also help health professionals to work more efficiently as they become aware of both the benefits of employment support for patients, as well as the potential to free up their clinical time through referring patients to specialist employment support. 
This was also a sense that joint working facilitated by WorkingWin has helped to improve mutual awareness of, and communication between, organisations with different remits. This supported the development of 'inter-organisational knowledge' as they learn about the respective priorities of key partners:

"We've found it an interesting process in terms of understanding some of the drivers of the organisations that perhaps that we weren't as familiar with, so particularly the health element of it. Understanding politically what their agenda is and what they're trying to achieve and it's then understanding, like, the context of what we're trying to do and how either of those things might rub against each other or might go along quite nicely so that's been probably one of the [biggest] learning curves for us". SCR

Finally, it was also noted that closer joint working through WorkingWin has also encouraged similar moves towards integrated approaches across other agendas. The SCR is now seeking, for example, to support the ICS around other health-related agendas where it is in a position to contribute to policy or strategy:

"And then again from the health and wellbeing position as well [the ICS] have got obviously targets around health and wellbeing for the region and targets around smoking and active travel that we can then support as well.... in terms of our agendas so we're having some quite fruitfulconversations with the ICS about joint shared objectives moving forward that go way beyond kind of the employment world into other things". SCR

\subsection{Future opportunities}

\subsubsection{Sustaining the legacy of WorkingWin}

There was a clear view among stakeholders that WorkingWin had proved its value and many advocated for continuing the service in some form to sustain its legacy:

"We got some really good outcomes from some service users. For us we would definitely buy into that." IAPT

"[There is] absolutely an appetite to do more" (ICS)

The trial was also seen to demonstrate significant demand for in-work support around health issues which had has been traditionally under-resourced:

"There is an awful lot of focus on getting people into work and less focus on keeping people in work, and supporting people in work... So in-work support is the real Cinderella and a lot of people would acknowledge that. Otherwise we are just doing the 'revolving door'. We just get people a job, we support them for a little bit, times get tough, they lose their job, they are out of work again. In-work support is a big element of prevention really". Public Health

Accordingly, many stakeholders expressed concern about the "the risk of having. a cliff face, in terms of things just disappearing" (SCR) as WorkingWin ends. There was a particular concern that local infrastructure in terms of networks and relationships that had developed around WorkingWin should not fizzle out:

"We've been talking about this a lot, as we now have GPs who have been referring and we need to be able to say this is what we can offer you now. It's really key as we want to keep their enthusiasm and build on that". Public Health 
"After a year when it stops, ...if you wait another six months then they go 'what is it again?'". Stakeholder Workshop

"As the programme was really taking off, the relationships were working, the referral pathways were understood, we stopped doing it!". (Local Authority)

"It will leave a gap that we won't be in a position to fill". (Local Authority)

Failing to develop some form of follow-on provision within relatively short timescales could see the loss of structures, partnerships and expertise that would have to be painstakingly rebuilt in any future iteration further down the road.

One related concern was that the landscape of employment support provision outside of WorkingWin was both confusing and fragmented. The restrictive eligibility criteria (e.g. of IPS schemes to those with severe mental health conditions only), time-limited nature, and lack of continuity and consistency between cycles of alternative programmes were seen to complicate the options facing health partners. This left partners with few alternatives to refer into:

"Now the referral window is closed, it's not easy to find something that is similar to be able to refer into. There are a couple of programmes, but not at the sort of scale". SCR

This highlights a need to build on the legacy of WorkingWin by commissioning further employment and health provision that provides a simple, clear and longer-term referral choice for clinicians looking to access employment support for clients or patients:

"The commissioning landscape for work and health stuff is pretty confusing. Provision from different providers, and who commissions what, and money from ESF...It's quite confusing. Making it simpler for referrers to build on the legacy of them actually thinking that work is a good idea is really important. And how we take what we have learnt from WorkingWin and build that into various commissioners' frameworks for what they commission or approaches that they ask providers to work by". Public Health

\subsubsection{The shape of future health and employment provision}

Stakeholders provided a number of suggestions on what any future iteration of integrated health and employment support should look like. Suggestions included:

- building provision directly into local structures in terms of commissioning and delivery as part of mainstream services, rather than being a standalone, experimental initiative.

- $\quad$ simplifying the complex and confusing landscape of employment support by having a limited number of employment support programmes with clear eligibility criteria.

- $\quad$ using social prescribing programmes pathways potential point of triage into future programme to streamline referral.

- rethinking the model as the high unit costs of the IPS model might not be sustainable if commissioned as mainstream provision:

"What we may end up with is a trial that shows it was worth doing but, actually, the cost to reinstate it, you know, and gather momentum, actually, might be pretty prohibitive." Public Health 
- $\quad$ continuing and expanding training for health professions around employment as a social determinant of health to address existing gaps in understanding and commitment from clinicians:

"There's a layer of health professionals that still think talking about employment doesn't fit with what I do. And so is there something legacy wise around offering training opportunities around why it is important". Stakeholder Workshop

One suggestion was to draw upon the considerable expertise in some other parts of the NHS around rehabilitation and supporting a return to work:

"There are pockets of the NHS who are very skilled at this. For example, rehab services, brain injury or physical disability where clinicians themselves can see it as their job to get people back to work because they are rehabilitating. And although we sort of do around the recovery model of mental health I don't think it is quite so explicit as it would be say if you talked to an occupational therapist, or a psychologist or a nurse or a speech therapist working in rehab services....I think there are cohorts where we might have learnt ...expertise from those areas of the NHS that are perhaps a bit more embedded with employment approaches". (Stakeholder workshop)

- Exploring the possibility of drawing down funding from a number of sources that could include:

- Employment and skills funding within local authorities and the combined authority as well as DWP and the European Social Fund (or successor scheme following Brexit)

- Securing funding for IAPT employment advisers that was previously withdrawn as a condition of funding WorkingWin

- Negotiating additional funding for health and employment through the forthcoming devolution settlement (see below).

- Maintaining the co-ordinating role of the SCR in managing any future commissioning, implementation and delivery of joint work-health provision.

- Ensuring that the promotion and development of joint employment and health support is embedded within key strategies and initiatives including:

- local authority and MCA strategies around employment, skills and economic development.

- the ICS' vision of reducing inequalities, improving population health and preventing ill health as laid out in its Five Year Plan

- $\quad$ linking any future provision into development of an SCR Employer Charter:

"We're looking at having an employer charter and kind of 'what does good look like?' for a business around health and wellbeing and them having access to support like that is then forming part of our thinking process around that". SCR

These suggestions provide the contours of what any future round of integrated work and health programming might like look. Along with earlier reflections in this subsection, there is a clear view that is essential to maintain the momentum built up around WorkingWin in terms of maintaining the local infrastructure - relationships, networks, structures (e.g. referral pathways), expertise and culture - that the programme fostered.

Moving at pace to secure some form of follow-on provision is vital, not least to ensure that clinicians have a referral option to support 'work as a health conversation' 
engagements with clients and patients. It will also avoid the tendency for organisations and services to slip back into funding and delivering provision within sectoral siloes, such as IPS provision being funded through NHS Trusts without connecting to the employment and skills expertise and employments programmes being delivered by local partners outside the NHS. There is a strong view that provision should be designed, commissioned and delivered locally and, crucially, funded through longer-term funding frameworks to avoid the short-termism and discontinuities created by time-limited or pilot initiatives.

As the SCR continues to negotiate its devolution ask and offer with central government, there may be opportunities to develop propositions based around securing additional monies and responsibilities to support the city-region in its efforts to build a sustainable work and health programme. To date, health has played a relatively minor role in devolution negotiations in the SCR. WorkingWin may therefore provide an opportunity to make a forceful case for SCR's capacity to deliver a complex cross-cutting agenda across traditionally siloed forms of working within the health and employment domains. As one interviewee suggested, WorkingWin can act as "the foot in the door" (ICS) to leverage greater devolution of powers across a range of agendas including employment, skills, welfare, health and housing that would be needed for a "step change" in developing fully integrated forms of support to help those with health conditions return to work.

There may also be opportunities to draw on experience and expertise within the health sector as it continues to support and deliver IPS. Sheffield is currently reaching the end of its Public Health England funded IPS alcohol and drugs trial. The ICS are also just beginning to deliver their own IPS provision in secondary mental health services as part of the NHS England ambition to double IPS provision nationally. This may open up space for conversations both locally and nationally about how funding, commissioning and delivery of integrated provisioncan be broadened out from delivery in 'pure' health service domains to encompass a wider range of partners and settings.

WorkingWin has, according to interviewees, demonstrated the value of key health services (ICS, CCGs, Trusts and clinical services) working with local and combined authorities and voluntary and community sector partners to deliver integrated health and employment support. It demonstrates how genuine joint working can occur at a local and city regional level, while also provided a platform to advocate for more integrated approaches with national funding partners. Critical here will be the willingness of WHU and parts of other central government to genuinely embrace devolved forms of joint working in ways that move beyond one-off pilot projects and afford even more control to local areas to shape interventions as they see best. 


\section{Sheffield Hallam University}

Co-design in the WorkingWin programme: good practice and learning

BEATTY, Christina <http://orcid.org/0000-0003-0943-9979>, CRISP, Richard $<$ http://orcid.org/0000-0002-3097-8769> and GORE, Tony <http://orcid.org/0000-00020997-7198>

Available from the Sheffield Hallam University Research Archive (SHURA) at:

http://shura.shu.ac.uk/27628/

\section{Copyright and re-use policy}

Please visit http://shura.shu.ac.uk/27628/ and http://shura.shu.ac.uk/information.html for further details about copyright and re-use permissions. 